\title{
Promoting cooperation in innovation ecosystems: evidence from European traditional manufacturing SMEs
}

\author{
Dragana Radicic (iD • Geoffrey Pugh • David Douglas
}

Accepted: 2 August 2018 / Published online: 28 August 2018

(C) The Author(s) 2018

\begin{abstract}
We investigate whether public support for innovation increases the propensity of SMEs in traditional manufacturing industries to cooperate for innovation - in particular, for incremental innovation-with other firms and external knowledge providers. Using data from seven EU regions, we find that support programmes do not promote cooperation with competitors, marginally promote cooperation with customers and suppliers and strongly promote cooperation with knowledge providers. These findings suggest that, in this case, the role of public policy is systems conforming rather than systems creating. Innovation support programmes can assist SMEs in traditional manufacturing industry to consolidate and/or extend their innovation ecosystems beyond familiar business partners by promoting cooperation with both private and public sector knowledge providers. Finally, our findings suggest that evaluation studies of innovation support programmes should be designed to capture not only
\end{abstract}

D. Radicic $(\bowtie)$

Department of Geography, University of Cambridge, Downing Place, Cambridge CB2 3EN, UK

e-mail: dr458@cam.ac.uk

G. Pugh

Centre for Applied Business Research, Faculty of Business, Education \& Law, Staffordshire University Business School, Leek Road, Stoke-on-Trent, Staffordshire ST4 2DF, UK

e-mail: g.t.pugh@staffs.ac.uk

D. Douglas

Faculty of Business and Law, Leeds Beckett University Business School, Leeds, Yorkshire LS1 3HB, UK

e-mail: d.j.douglas@leedsbeckett.ac.uk input and/or output additionality but also behavioural and systemic effects.

Keywords SMEs · Traditional manufacturing industry · Innovation ecosystems · Innovation policy · Cooperation for innovation $\cdot$ Behavioural additionality

JEL codes $\mathrm{O} 31 \cdot \mathrm{O} 38 \cdot \mathrm{H} 32 \cdot \mathrm{C} 21 \cdot \mathrm{L} 26$

\section{Introduction}

Gomes et al. (2016) chart the transition from the business ecosystem to the innovation ecosystem concept, demonstrating that in this joint literature 'innovation' has been the most cited keyword since 2006 and that, since 2011, both 'networks' and 'collaboration' have joined the list of the 10 most cited keywords. These concerns reflect the systems view that innovation is an interactive process; in particular, that innovative firms require the creation of a cooperative network, which is essential for their evolution (Scaringella and Radziwon 2018). We extend this literature by providing evidence that public support programmes, by promoting cooperation, can contribute to the well-functioning of innovation ecosystems in traditional manufacturing industries, a context which - to the best of our knowledge - has not yet been explored by the innovation ecosystems literature and is largely ignored in the wider innovation literature. To this end, we evaluate whether and, if so, to what extent innovation support programmes for 
European SMEs in traditional manufacturing industries induce cooperative behaviour for innovation.

The importance of cooperation is a corollary of evolutionary perspectives on innovation as the outcome of systems. In contrast to mainstream theories motivating public support for innovation, the evolutionary perspective points to the central role of cooperation and thus coevolution between institutions in the functioning of systems of innovation (Chaminade et al. 2018). According to Mazzucato (2016, p. 99), the 'evolutionary emphasis on transformation and structural change has led to the concept of "systems of innovation", which posits that firms are embedded in a national network of institutions - in both public and private sectors'. From this perspective, innovation outcomes are influenced by the quantity and quality of cooperation between the institutions in the network. The recent innovation ecosystems literature also highlights the importance of firms' cooperation for innovation (Durst and Poutanen 2013; Gobble 2014). According to Gobble (2014, p. 55), innovation ecosystems can be defined as 'dynamic, purposive communities with complex, interlocking relationships built on collaboration, trust, and co-creation of value and specializing in exploitation of a shared set of complementary technologies or competencies'. ${ }^{1}$ The concept is similar to the theories of national and regional innovation systems, insofar as both theoretical perspectives regard innovations as open and interactive processes, although the ecosystems concept places greater emphasis on the role of market forces (Papaioannou et al. 2009; Durst and Poutanen 2013; Oh et al. 2016). Innovation ecosystems, whether at national or regional level, include the same players-i.e. companies, universities, entrepreneurs, customers, regulatory agencies and government bodies at all administrative levels (Gobble 2014). Moreover, there is an affinity between recent literature on entrepreneurial ecosystems and the literature on innovation systems, especially the focus on the relational elements within multi-actor networks at the regional level (Acs et al. 2017; Brown and Mason 2017).

Oh et al. (2016, p. 5) identify limitations of the emerging ecosystems approach to understanding innovation, including: (i) the emphasis on market forces ('business-only ecosystem') 'seems inconsistent with the trend to open innovation'; (ii) 'special kinds of

\footnotetext{
${ }^{1}$ The literature does not provide a robust definition of innovation ecosystems and Oh et al. (2016) argue that the concept adds very little to the traditional systems of innovation approach.
}

complex system behaviour have yet to be substantiated'; and (iii) it 'offers no ready metrics'. Together, these limitations provide a context for the contribution of this study, which evaluates the role of public policy in promoting cooperation as a measurable outcome. Evaluation of innovation policies has been mainly conducted within the confines of mainstream theories of public support for innovation and, hence, has mainly been concerned with input and output additionalities. Yet focussing on innovation inputs and outputs means that we stay outside the 'black box' of innovation processes (OECD 2006). Conversely, broadening the theoretical underpinnings of evaluation studies to include evolutionary insights and systems perspectives on innovation enables more complete assessment of the impact of public measures on firms' innovative behaviour (Buisseret et al. 1995; Georghiou and Clarysse 2006). In particular, cooperation potentially induced by innovation support programmes is a form of behavioural additionality (OECD 2006; Falk 2007; Wanzenböck et al. 2013). ${ }^{2}$ This study contributes to this broader approach to the evaluation of innovation support policies by analysing the same dataset as [Radicic et al. 2016, p. 1425] who report that 'for participants, the estimated effects of publicly funded innovation support programmes on SMEs in traditional manufacturing industries are positive, typically increasing the probability of innovation and of its commercial success by around $15 \%$. In this study, we report that the innovation support programmes investigated by [Radicic et al. 2016] give rise in addition to behavioural benefits in the form of 'network or cooperation additionality'. In turn, in Section 3 below, we argue that by giving rise to more cooperation than there would otherwise be (i.e. in the no policy support counterfactual), innovation support programmes may contribute to the well-functioning of innovation ecosystems and thus promote cooperative innovation performance in ways not accounted for in traditional evaluation studies. Accordingly, our main research question is whether public support measures

\footnotetext{
${ }^{2}$ Behavioural additionality is defined broadly as the effect of public intervention on firms' innovative behaviour (Buisseret et al. 1995). However, in common with most empirical studies (Georghiou and Clarysse 2006), we investigate only the impact of public intervention on firms' cooperative behaviour, which is defined variously as scope additionality (Falk 2007) or network additionality (OECD 2006). Scope or network additionality occurs when the likelihood of a firm cooperating for innovation increases as a result of participation in a support programme (Busom and Fernández-Ribas 2008).
} 
are effective in fostering cooperative behaviour among SMEs in traditional manufacturing industries.

We draw on a unique dataset of SMEs in six industries across seven EU regions and employ matching estimators to investigate the impact of public support measures on cooperation for innovation. Because all of the SMEs in the dataset are in manufacturing industries commonly described as 'traditional', and few such firms receive support for $\mathrm{R} \& \mathrm{D}$ activities, the support measures investigated in this study are the ones designed to promote both technological and non-technological innovation outputs (as defined in the Oslo Manual, OECD 2005). ${ }^{3}$ The next section explains why it is important to investigate SME behaviour within the particular context of traditional manufacturing industry, rather than within broader, less differentiated sector(s); and why, in consequence, this study also contributes towards understanding SME cooperation in the context of incremental innovation. Given that we focus on SMEs, that traditional manufacturing industry is a coherent unit of analysis, mainly conducting incremental innovation, and that the relevant mix of public support programmes is distinct, we cannot assume that the hypotheses informed by the literature-which is both scarce and relating to other contexts - are completely appropriate for the investigation in this article. Accordingly, in Section 3, in the absence of a relevant literature on traditional manufacturing in general and on traditional manufacturing SMEs in particular, our hypotheses are informed both by the existing literature and by the context of our investigation.

\section{Context: the continuing importance of traditional manufacturing industry and the focus on incremental innovation}

One novelty of this study is its focus not only on SMEs but, specifically, on SMEs in traditional manufacturing industry. Radicic et al. [2016, p. 1427] eschew the identification of traditional manufacturing with 'low-

\footnotetext{
${ }^{3}$ Firms in traditional industries receive more support than do firms in other manufacturing sectors from the following measures [Radicic et al. 2016]: subsidies and loans for acquiring machinery, equipment or software; support for internationalisation, e.g. by providing financial assistance for attending or participating in trade fairs or trade missions; networking with other companies; brokering collaborations - e.g. with outside experts, with universities or with large firms' supply chains; and providing information on market needs, market conditions, new regulations, etc.
}

tech', instead of defining traditional manufacturing industry as a coherent unit of analysis in terms of a number of related characteristics: long established; once a main source of employment, at least at the sub-regional level; in the mature or declining phase of their industry life cycle, with recent decline typically associated with globalisation; relatively labour intensive, hence vulnerable to out-sourcing to other countries; but retaining a capacity for innovation, 'through which they continue to be important sources of wealth creation and employment'. The authors also document that traditional industries conceptualised in this manner include the six considered in this study and that, in the period 2009-2012, these six industries accounted for upwards of $40 \%$ of all manufacturing jobs in the seven EU regions considered in this study. Moreover, 'the importance of traditional manufacturing industry is not confined to these seven regions but is common throughout the EU' [Radicic et al. 2016, p. 1430]. Indeed, 'in around half of EU regions, the share of these traditional industries in manufacturing employment increased over these 15 years [1995-2009]; and in 78 EU regions, the increase exceeded $4.5 \%$ '. Although rather neglected by the innovation literature, traditional manufacturing remains an important source of employment and wealth creation in the developed economies. Our investigation of cooperation for innovation in traditional manufacturing industry is thus not a novelty for its own sake but responds to policy concerns throughout the EU and in the USA to better understand and promote traditional sector innovation [Radicic et al. 2016, pp. 1427 and 1430].

A further contribution of the present study is a corollary of our focus on cooperation for innovation by SMEs in traditional manufacturing industries, namely, an implied focus on incremental innovation. In discussing the slowdown of productivity growth across the developed market economies, Nobel Laureate Edmund Phelps (2015, p. 56) conjectures that: 'The plausible explanation of the syndrome ... is a critical loss of indigenous innovation in the established industries like traditional manufacturing and services that was not nearly offset by the innovation that flowered in a few new industries - digital, media and financial.' While Phelps does not use the term 'radical innovation', his concept of indigenous innovation is similar. The corollary is that in the context of traditional manufacturing industry, current innovation is largely incremental, which is consistent with Faems et al. (2005). This implication is reinforced by our focus on SMEs, given 
evidence consistent with the Schumpeter (1942) hypothesis that large firms are the ones with the greatest propensity to introduce products with higher degrees of novelty (O'Connor and DeMartino 2006; O'Connor 2008, p. 62; Tellis 2013, p. 240). Previous studies of cooperation have emphasised that the degree or breadth of cooperation is important in enhancing firms' abilities to develop radical innovation; indeed, that 'collaboration was more frequent among firms pursuing higher level rather than incremental innovations ... because ... firms introducing innovations with a greater degree of novelty are more likely to use a wider range of information sources to develop or improve their products' (Nieto and Santamaria 2007, p. 368, citing Tether 2002; and Amara and Landry 2005). The context of the present study is thus not only a contribution in its own right but also entails the additional contribution of investigating cooperation for innovation where innovation is overwhelmingly incremental (Faems et al. 2005).

\section{Literature review: innovation support programmes and cooperation for innovation}

\subsection{Innovation ecosystems, cooperation and public support programmes}

The ecosystems approach to understanding innovation has an affinity with open innovation theory (Chesbrough 2003) in moving beyond individual firm performance to focus on knowledge transfer within cooperative relationships between firms and related institutions (Durst and Poutanen 2013; Oh et al. 2016; Song 2016). However, thinking on ecosystems seems to suggest in addition a cumulative causation effect. On the one hand, cooperation at the micro level is one of two core attributes, along with integrated value chains, of innovation ecosystems (Xu et al. 2018). This is consistent with Song (2016, p. 14): ' ... multiple organisations ... integrate their resources and form an environment that leads to the research and development of new technological applications ... and improves the innovation ecosystem's cooperative performance'. On the other hand, there may be emergent properties at the macro or system level that enhance innovation and enlarge the scope for cooperation at the micro level. For example, the greater the technological diversity of firms' alliance partners, the greater their 'exploratory innovation' (according to Phelps and Paris 2010, cited by Song
2016, p. 14). Yet, from the perspective of the wider innovation ecosystem in which these firms are located, the greater the technological diversity, the greater the opportunities for all firms to cooperate to innovate more complex products that are harder to imitate and thus a source of individual competitive advantage (drawing on Song 2016). In this case, firm-level cooperation for innovation is at the base of an 'ecosystem' whose emergent properties give rise to positive feedback on cooperative innovative performance at the firm level ... and so on. In this case, estimating the effects of public innovation support programmes on firms' cooperative behaviour (whether intended or unintended) is a contribution to understanding the role that public policy may play in contributing to the well-functioning of innovation ecosystems. Moreover, a corollary of this potential to propagate innovation via a process of cumulative causation (firm-ecosystem-firm ... and so on) is that the effects of public innovation support policies may unfold over time and thus go beyond the immediate and short-run innovation effects-innovation inputs (e.g. R\&D expenditure) and outputs (e.g. technological and non-technological innovations) - that dominate the evaluation literature.

In spite of the emphasis on market mechanisms in innovation ecosystems thinking, this emerging literature does embrace the role of public policy. ${ }^{4}$ The particular focus of our study is on the effectiveness of public support in promoting firms' cooperative behaviour, which supports the dynamism of innovation ecosystems. The literature evaluating innovation support programmes has previously highlighted the impact of public support on firms' cooperative ties, whether through networking or partnerships with other economic agents (Georghiou 2004; Hall and Maffioli 2008; Breschi et al. 2009; Antonioli and Marzucchi 2012). Accordingly, public intervention might enable firms to establish cooperative ties or strengthen existing ones (Aschhoff et al. 2006). In turn, by engaging in external relations, firms acquire and improve knowledge and learning capabilities (Clarysse et al. 2009; Afcha Chàvez 2011).

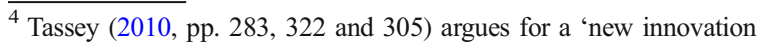
model ... to guide economic growth policy' in the USA and that the 'overriding policy question is how to expand and improve the efficiency of this (i.e. the national US) increasingly complex and diversified innovation ecosystem'. To this end, the 'government role will require both larger R\&D spending and new and more efficient mechanisms for $\mathrm{R} \& \mathrm{D}$ funding and technology diffusion'.
} 
From different theoretical perspectives, government intervention to promote cooperation for innovation may stem from incomplete appropriation of knowledge spillovers generated through cooperative ties, systemic failures reducing firms' willingness to cooperate or resource limitations reducing their ability to cooperate. For example, public support might encourage internalisation of knowledge spillovers from cooperation (i.e. learning effects) as a complementary objective to fostering firms' innovation activities (Autio et al. 2008; Afcha Chàvez 2011). In other words, public intervention might yield 'a learning-enhancing externality beyond the direct effect of firm-specific R\&D subsidy' (Autio et al. 2008, p. 60).

The literature evaluating innovation support programmes, in particular that part embracing behavioural additionality (influenced by evolutionary thinking), identifies ways in which public support may positively influence cooperative behaviour (Antonioli and Marzucchi 2012; Gök and Edler 2012). Buisseret et al. (1995) introduced the concept of behavioural additionality to describe the change in firms' behaviour as a consequence of public policy. It refers to knowledge acquisition and developments of learning and R\&D management capabilities, competencies and strategies, including cooperation strategies (Antonioli and Marzucchi 2012; Gök and Edler 2012; Wanzenböck et al. 2013). Georghiou (2002) hypothesised that behavioural additionality can occur as a consequence of public interventions even when input and/or output additionality does not take place, although this is contested by Clarysse et al. (2009, p. 1524) who argue on both theoretical and empirical grounds that input additionality and behavioural additionality are "highly correlated'. Although scarce, most empirical studies on behavioural additionality focus on firms' cooperation strategies and report positive effects from innovation support programmes (Fier et al. 2006; Busom and Fernández-Ribas 2008; Fernández-Ribas and Shapira 2009). Of these, most report larger additionality effects for public-private partnerships than for cooperation with other businesses (Fier et al. 2006; Busom and Fernández-Ribas 2008). Indeed, Afcha Chàvez (2011) and Antonioli et al. (2014) report no innovation policy effects on vertical cooperation (with customers and suppliers), while the latter even found a negative impact of regional policy on horizontal cooperation (with competitors). In summary, most studies report positive effects of innovation support programmes on firms' cooperation behaviour, but the magnitude and significance vary depending on the type of cooperative partnerships.

Table 7 in the Appendix highlights the main features of the previous empirical studies on behavioural additionality, all of which encompass cooperation, and enumerates the main differences with the present study. Few studies have expressly focussed on behavioural additionality across country boundaries, with a focus on either a single country (Falk 2007; Busom and Fernández-Ribas 2008; Clarysse et al. 2009; Hsu et al. 2009; Afcha Chàvez 2011; Wanzenböck et al. 2013) or region (Antonioli et al. 2014). Only one study, with limited coverage, included traditional sectors (Falk 2007), although it reports no specific results for traditional manufacturing. Heterogeneity by firm size was not investigated in any of the studies, with only a few investigating heterogeneity by source of funding: Afcha Chàvez (2011) -EU funding not separately identified; Wanzenböck et al. (2013) - national funding only; and Antonioli et al. (2014)—regional funding only. This study makes its particular contribution by drawing upon a cross-country sample, by focussing exclusively upon traditional manufacturing industries (otherwise neglected in the literature, as we argue in Section 2 above), and by investigating policy effects on SME cooperative behaviour with respect both to firm size heterogeneity and to different sources of funding. Accordingly, the present study complements the existing literature.

Innovation support programmes used by SMEs in traditional manufacturing industry mainly target innovation outputs, although some seek to promote cooperative behaviour in particular. However, the literature suggests that innovation support of all kinds tends to promote behavioural change, whether directly or indirectly, including the propensity to cooperate. This perspective informs the present study by suggesting that it is reasonable to analyse the behavioural effects of participation in all types of innovation support programmes. The next section explains how cooperation for innovation informs hypotheses that we can test using our data on SMEs in traditional manufacturing.

\subsection{Hypothesis development}

The literature identifies many advantages of cooperation for innovation: cost reduction by exploiting economies of scale and scope (Hagedoorn 1993; Teirlinck and Spithoven 2012); sharing risk and uncertainty related to innovation (Hagedoorn 1993; Rese and Baier 2011); 
and opting to 'buy', instead of 'make', when transaction costs are low (Williamson 1985). In addition, 'speed to market' is particularly important for SMEs-i.e. rapid commercialisation of inventions to capture innovation returns and overcome appropriability issues (Leiponen and Byma 2009; Rese and Baier 2011). Yet Hoffmann and Schlosser (2001) find that SMEs greatly underestimate some of the critical success factors for successful cooperation, such as partnership governance and professional management, and often lack the managerial skills and experience necessary for developing and maintaining successful cooperative ties. In turn, this suggests a channel through which public support for any type of innovative activity-i.e. by relieving resource constraints - may help to promote cooperative activity.

The literature not only identifies advantages of cooperation but also suggests circumstances that condition firm preferences regarding types of cooperation. We now explain how theory, which relates mainly to firms in general rather than to SMEs in particular; characteristics of SME innovation in traditional manufacturing industry; and the data available for this study together lead us to frame hypotheses regarding SME cooperation with customers and suppliers, competitors, private knowledge providers and public knowledge providers.

Different types of cooperative partner entail different breadth of knowledge base and ease of access (Un et al. 2010). With respect to vertical cooperation with customers and suppliers, cooperation with suppliers is characterised by a limited scope of knowledge breadth, because often the focal firm and its suppliers operate in similar industries, but the focal firm can access that knowledge more easily than when cooperating with customers. On the other hand, cooperation with customers provides firms with broader knowledge but more limited access (Un et al. 2010).

Following the resource-based theory of the firm, in cooperating for innovation, firms can seek to access either complementary or similar resources (Arranz and de Arroyabe 2008; Chun and Mun 2012). The main reason for vertical cooperation on innovation is that firms gain access to complementary resources and capabilities (Arranz and de Arroyabe 2008; Un et al. 2010). By providing technological knowledge, suppliers usually help firms to improve their current products, introduce new products and/or reduce costs through process innovation (Belderbos et al. 2004; Un et al. 2010), while cooperation with customers is particularly relevant in the commercialisation phase of innovation (Von Hippel 1988; Belderbos et al. 2004; Arranz and de Arroyabe 2008). In industries with a mature technological level, such as traditional manufacturing, firms cooperate with customers to exploit and optimise existing technologies (Faems et al. 2005). Moreover, the importance of 'speed to market' for SMEs (noted above) may apply with particular force to traditional sector SMEs; because they seldom register patents or engage in other formal ways of protecting intellectual property rights (Leiponen and Byma 2009), cooperation to secure deliveries from suppliers and/or sales to existing customers may be a particular priority. In line with this discussion, we investigate Hypothesis 1 : The impact of public support has a positive impact on vertical cooperation with customers and suppliers.

Mutual trust between partners is often identified as a key success factor in collaborative relationships (Barge-Gil 2010; Lee et al. 2010). As a potential partner can behave opportunistically and obtain information about new technologies without paying for them, firms may lack incentives to reveal their internal inventions. Accordingly, empirical studies regularly report that weak appropriability has a negative effect on cooperation for innovation (Lhuillery and Pfister 2009). Barge-Gil (2010) concludes that forcing firms to collaborate can be counterproductive and creates a climate of mistrust, while Lee et al. (2010) discuss potential negative effects of cooperation in the context of small and medium-sized firms. Conversely, public support measures might help firms to overcome barriers to cooperation as well as to mitigate cooperation failure (Busom and Fernández-Ribas 2008).

Cooperation failure refers to reduced effort in cooperative partnerships when cooperating firms do not clearly specify which partner will be assigned exclusive property rights (Dhont-Peltrault and Pfister 2011). In particular, SMEs might face a higher risk of cooperation failure in cooperating with competitors (Lhuillery and Pfister 2009). Competing firms could try to capture the other firm's knowledge (i.e. to maximise incoming spillovers) while, at the same time, trying to minimise the transfer of their own knowledge to the other firm (to minimise outgoing spillovers) (Belderbos et al. 2004).

With respect to knowledge breadth and its accessibility, cooperation with competitors is an extreme case, as it provides rather limited knowledge breadth accompanied by difficulties in accessing it (Un et al. 2010). The resource-based theory of the firm suggests that firms cooperate with competitors to gain access to 
similar knowledge bases and resources (Arranz and de Arroyabe 2008; Un et al. 2010). The main motive for collaborating with competitors is risk and cost sharing in innovation projects by pooling similar resources (Miotti and Sachwald 2003; Arranz and de Arroyabe 2008; van Beers and Zand 2014).

Cooperation with competitors is particularly pertinent to firms in high-tech industries, which are more likely to cooperate with their rivals to pool costs and risks and increase the speed to new markets (Arranz and de Arroyabe 2008). Conversely, the cost and risk drivers may be less compelling and speed to market more compelling for firms in traditional manufacturing, which are low- and medium-tech. Responses from the surveyed firms in our sample are consistent with this conjecture, as the smallest number of firms (27 or 9\%) cooperate with competitors, while the largest number engage in vertical cooperation with customers and suppliers (see Section 5.1), which is common with respect to cooperation for innovation (Lhuillery and Pfister 2009). Moreover, a low proportion of firms cooperating with competitors may be taken as an indicator of the difficulties of managing this type of relationship.

In sum, following Lhuillery and Pfister (2009), the risk of cooperation failure is of high importance when a firm decides whether to cooperate for innovation with a particular partner, and this may apply with particular force to traditional sector SMEs that tend not to use formal means to protect intellectual property. Very few empirical studies report behavioural additionality with respect to cooperation with competitors. Indeed, Antonioli et al. (2014) found a negative impact of regional policy on this type of cooperation. Therefore, we posit Hypothesis 2: The impact of public support on cooperation with competitors will yield a smaller treatment effect than will other forms of cooperation, given the likelihood of cooperation failure due to mistrust and opportunistic behaviour.

Theoretical and empirical studies on the role of consultants and other private sector knowledge providers in 'systems of innovation' are rather scarce (Tether and Tajar 2008). With respect to specialist knowledge providers, Tether and Tajar (2008) argue that they are complements rather than substitutes in firms' innovation activities. This argument is in line with the open innovation model, in which firms explore a broad range of external knowledge sources. In addition, Tether and Tajar (2008) found that similar factors determine relationships between firms and either specialist knowledge providers or public research organisations. In particular, they report that firms with limited investment in $R \& D$ are more prone to cooperating with consultants than with other private or public knowledge providers, an argument that may be particularly relevant to traditional sector SMEs whose intellectual property is more typically tacit than the product of formal R\&D. This is partially reflected in our data, whereby a larger portion of firms cooperate with consultants than with government institutions and public research institutions; see Table 8 in the Appendix. (Higher education institutions - HEIs - are an exception, but that is understandable given the increased pressure on universities to collaborate more closely with industry.) In the absence of theory and empirical study of the public support effects on SME cooperation with private sector consultants, we conjecture that these are similar to support effects on public-private partnerships. Moreover, if these effects are different, they are likely to be smaller if private sector consultants are less trusted than public sector bodies with knowledge leakage. Accordingly, we frame Hypothesis 3: The impact of public support on partnerships with private sector consultants is positive, and the magnitude of treatment effects is equal to or less than the impact of public-private partnerships.

The main motive for cooperation with public institutions, such as HEIs and research institutes, is access to basic knowledge, which might lead to entering new markets (Belderbos et al. 2004; Faems et al. 2005). This might also apply with particular force to firms with limited investment in R\&D, which includes traditional sector SMEs. Other arguments from the literature are likewise particularly relevant to traditional sector SMEs. Concerning knowledge breadth, cooperating with public institutions provides firms with the broadest knowledge base (Un et al. 2010). Moreover, this mode of cooperation entails the greatest ease of access, compared to vertical and horizontal cooperation, as well as low risk of knowledge leakage and opportunistic behaviour. Cooperation with public institutions will be particularly prominent in firms further away from the technological frontier, as their technological and financial resources are rather limited (Miotti and Sachwald 2003; Faems et al. 2005). The confirmation of this argument can be observed in our sample; namely, descriptive statistics indicate that one third of SMEs cooperate with HEIs, which is a similar proportion to the number of firms engaged in vertical cooperation with customers and suppliers (see Appendix Table 8). This finding is further 
in line with the argument that universities provide the largest knowledge base relative to any other cooperative partner (Un et al. 2010; Foreman-Peck 2013).

Finally, given the prominent role of trust in cooperative innovation, firms are least likely to trust their competitors and most likely to trust government institutions, which are willing to share knowledge with enterprise while posing no commercial threat. Thus, appropriability issues and mistrust are least likely to occur in publicprivate partnerships, which may be particularly important for traditional sector SMEs that may not engage in formal protection of intellectual property. Furthermore, Cassiman and Veugelers (2002) report that incoming spillovers (using external knowledge sources) are an important factor in private-public partnerships. Conversely, the presence of technological information reduces the probability of vertical cooperation with customers and suppliers. Therefore, we formulate Hypothesis 4: The impact of public support on public-private partnerships (cooperation with HEIs, government institutions and public research centres) is positive, and the magnitude of treatment effects is the largest relative to other types of cooperation.

\section{Methodology}

Empirical evaluation of public support requires econometric methods that take into account the potential endogeneity of public support (David et al. 2000). With respect to behavioural additionality, endogeneity of public support may arise from simultaneity or/and unobserved firm characteristics that influence both the probability of receiving innovation support and the probability of establishing and maintaining cooperative relationships (Busom and Fernández-Ribas 2008). In both cases, estimated programme effects are biased and inconsistent. In Section 5.2 below, we present evidence consistent with the interpretation of our findings as programme effects on firms' cooperative behaviour rather than as reflecting reverse causation (i.e. the possibility that causation also runs from cooperation to programme participation). Here, we focus on the potential problem of unobserved heterogeneity. In our case, the potential for endogenous programme selection is likely to be substantially attenuated, because most support programmes focus on innovation outputs rather than on cooperation. Hence, selection on unobservable firm characteristics is likely to be more influenced by unobserved aspects of firms' innovation behaviour than by unobserved aspects of firms' cooperation behaviour. Nonetheless, we address this crucial methodological issue for two reasons: firstly, some support programmes do explicitly address cooperation as an output and so might be subject to biased selection by programme managers; and, secondly, those firms most inclined to cooperate may be the ones with the greatest propensity to self-select into support programmes (Foreman-Peck 2013; Czarnitzki and Delanote 2015).

We estimate the average treatment effect on the treated (ATT), which indicates the difference in outcomes for the treated firms (i.e. firms participating in support programmes) with and without treatment and can be written as:

$\mathrm{ATT}=E\left[Y_{1} \mid T=1\right]-E\left[Y_{0} \mid T=1\right]$

The first term on the right-hand side of Eq. (1), $E\left[Y_{1} \mid\right.$ $T=1]$, is the expected $(E)$ outcome for treated firms $\left(Y_{1}\right.$, where subscript 1 indicates participation) conditional on their participation $(T=1)$, while the second term $E\left[Y_{0} \mid\right.$ $T=1]$ is the expected outcome had treated firms not participated in the public support programme (where subscript 0 indicates counterfactual non-participation). This second counterfactual outcome is not observed but estimated. Matching estimators, such as the propensity score matching (PSM), are the most frequently used estimators in innovation studies (Herrera and Nieto 2008; Cerulli 2010). We follow this practice but adopt the recommendation from the wider evaluation literature to test for hidden bias (i.e. unobserved heterogeneity, see below) (Guo and Fraser 2010). The main limitation of matching estimators is selection on observables, i.e. this method only controls for firms' observed characteristics (Nannicini 2007; Caliendo and Kopeinig 2008; Guo and Fraser 2010). In cases when unobserved firm characteristics influence the treatment assignment, matching yields biased estimates.

Matching as an evaluation method is based on two identifying assumptions. The first is the conditional independence assumption (CIA), unconfoundedness or selection on observables (Imbens 2004). This condition states that the outcomes $Y_{0}$ and $Y_{1}$ are independent of treatment assignment $T$, conditional on observed covariates $X$. The CIA is a strong assumption and requires that all relevant observed variables are included in the estimation of treatment effects (Caliendo and Kopeinig 2008; Steiner et al. 2010) and that variables are measured 
before treatment assignment (or that they measure fixed or slow-moving firm characteristics such as those associated with otherwise unobserved industrial and regional influences, which we capture by industry and region dummies). The second refers to the overlap or common support condition, which states that both treated and nontreated firms have a positive probability of receiving a treatment or not (thus avoiding perfect predictability of a treatment assignment conditional on $X$ ).

Regarding choice among the PSM methods, nearest neighbour $(\mathrm{NN})$ matching is the most commonly used estimator in the innovation literature (Herrera and Nieto 2008). In applying the NN estimator, subsidised (treated) firms are matched with non-subsidised firms (as a control group) with the closest estimated propensity scores. The crucial step in the matching procedure is the choice of covariates $X$. The literature suggests that all observed variables that simultaneously affect a treatment and an outcome should be included in the estimation of propensity scores (the selection equation) (Caliendo and Kopeinig 2008; Steiner et al. 2010).

Since the propensity score is the probability of receiving a treatment (in our case, public subsidies), researchers can choose any discrete choice model, because both probit and logit models usually yield similar results (Caliendo and Kopeinig 2008). After the estimation of the propensity score, but prior to applying a chosen matching estimator, a balancing test should be conducted. The purpose of a balancing test before matching (stratification test) is to check how well the estimated propensity score has succeeded in balancing covariates. We applied the procedure by Becker and Ichino (2002), similar to the study by Herrera and Nieto (2008). After the propensity score is estimated, and if matching quality is satisfactory, the matched pairs of treated and non-treated firms are created, based on the estimated propensity score. Finally, the ATT is calculated by taking the mean difference in the outcome variables of the matched treated and non-treated firms.

As a robustness check, the literature on evaluation methods recommends the estimation of treatment parameters applying different matching estimators (Herrera and Nieto 2008; Guo and Fraser 2010). We apply two alternative approaches: kernel matching and inverse probability of treatment weighting (IPTW, i.e. the 'double robust' estimator). Finally, we use two approaches to sensitivity analysis to check whether the estimated treatment effects are robust with respect to unobserved heterogeneity (see Section 6.1).

\section{Data and variables}

\subsection{Data}

This study employs a unique survey dataset gathered in 2010, while the survey questionnaire covers the period 2005-2009. The sample comprises 312 SMEs in traditional manufacturing industries from seven EU regions, mainly ( $80 \%$ ) belonging to one of six manufacturing industries strongly represented in these regions. ${ }^{5}$ Descriptive statistics are presented in Appendix Table 8. Fewer than half of the surveyed firms $(45 \%)$ participated in one or more public support programmes in the period covered by the survey. The modal firm in the sample had 35 employees. ${ }^{6}$ Regarding cooperation partners, the largest number of firms stated that they engaged in vertical cooperation (34\% of firms cooperated with customers and $33 \%$ with suppliers), followed by cooperation with HEIs $(31 \%)$ and with consultants $(22 \%)$. A small number of firms stated they engaged in horizontal cooperation with their competitors (9\%). In addition to summary statistics for the full sample, we also report summary statistics for micro, small and medium-sized firms. The average values of the treatment and outcome variables are similar for different firm size categories.

Afcha Chàvez (2011, p. 106) notes that the 'relatively scarce' empirical evidence on behavioural additionality arises from 'data collected through interviews and small surveys'. This applies to most of the papers detailed in Table 7 in the Appendix as well as to the present study. Within this constraint, the sample is drawn from seven regions in which traditional manufacturing industries are prominent in the regional economy (as noted in Section 2) and omits only one of the industries (chemicals) categorised as 'traditional manufacturing' by the European Commission's European Service

\footnotetext{
$\overline{5}$ Details on how the sample was obtained in different regions are available in: GPrix Deliverable 3.3, p. 20, and Deliverable 1.7, especially pp. 10-14. Deliverable 1.7, pp. 16-54, also reports exhaustive descriptive statistics on the sample. These documents are available from: http://business.staffs.ac.uk/gprix/en/index.htm (click on the 'Reports' tab). The dataset in Stata format together with 'Do-files' containing the syntax used in estimation and unpublished appendices are available from http://www.staffs.ac.uk/research/cabr/working-papers/.

6 The proportion of micro, small and medium-sized firms in the sample is reasonably well balanced: $33 \%$ are micro firms with fewer than 10 employees; $43 \%$ are small firms with 10 or more and fewer than 50 employees; and $24 \%$ are medium-sized firms with 50 or more and fewer than 250 employees (see Appendix Table 8).
} 
Innovation Centre (ESIC) (European Commission 2015). ${ }^{7}$ Following Radicic et al. [2016], our sample was designed to be useful for informing policy. According to the Oslo Manual 'broad' definition of innovation (OECD 2005), from the 312 SMEs in our sample, 294 (94\%) recorded innovative activity within the sample period. Taking into account good balance - even before matching - between participants and non-participants in innovation support programmes, as well as between firms of different sizes within the broad SME category, our sample is uniquely informative about the potential of public programmes to promote cooperation among a type of firm that matters to policy makers, namely, innovating SMEs in traditional manufacturing industries.

Variations in regional (country) contributions to the sample are to be understood in the context of known difficulties of obtaining questionnaire responses from SMEs [Radicic et al. 2016], while industry variations broadly reflect differences in the size of sectors (e.g. 'Ceramics'-7.8\% of the sample firms - accounts for just one of the 3-digit components of SIC 2007 Division 23, while 'Metal manufacturing'-29.8\% of the sample firms - accounts for two 2-digit divisions, 27 and 28). To anticipate the findings of Section 6.3 below, we find that our matching estimates are robust to industry heterogeneity and that only in one case- the effect of programme participation on cooperation with government research centres - is an estimate not robust to country heterogeneity.

We do not control for firm age. Indeed, this question was deliberately omitted from the questionnaire, because there was unlikely to be sufficient contrast between young (less than 6 years) and older firms - the usual distinction in the literature - to provide a useful control variable in subsequent modelling. Our questionnaire had to be restricted to a length consistent with gaining responses (the equivalent of four A4 sides including introductory material). Hence, questions were omitted where we had good reason to do so. In this case, our definition of 'traditional' as in part defined by 'long established' applies also to our sample SMEs. From the 39 case studies that accompanied our survey, only the four French firms have an average year of establishment after 1980, while eight firms (20\%) could date their foundation only approximately: for example, 'early

\footnotetext{
${ }^{7}$ See http://ec.europa.eu/growth/tools-databases/esic/about/ keywords/index_en.htm.
}

1960s', 'pre-1960', 'late 1800s' and '1800s'. Otherwise, omitting those firms whose year of establishment could not be precisely dated, the average year of establishment is as follows: Germany-1949; Spain-1966; France1998; Italy_-1973; Netherlands_-1977; Portugal_1971; and UK - 1943. Not only are there no young firms in our sample but, since their establishment, many of these firms have changed greatly with respect to, for example, size, product mix and ownership.

\subsection{Model specification}

The treatment variable (Participation) is a binary indicator equal to 1 if the firm responded positively to the question: 'Did your enterprise during the five years 2005 to 2009 receive any public support for your innovation activities?' The seven outcome variables measuring firms' cooperation activities are defined as binary indicators equal to 1 if the firm cooperates with the following potential partners (and 0 otherwise): suppliers (Coop_suppliers); customers (Coop_customers); competitors (Coop_competitors); consultants (Coop_consultants); HEIs (Coop_HEIs); government research centres (Coop_government); and public research centres (Coop_centres) (see Appendix Table 8 for descriptive statistics).

Control variables include a continuous variable (Size) to account for the heterogeneity of SMEs. Following Busom and Fernández-Ribas (2008), the literature suggests an ambiguous association between firm size and cooperation for innovation. We model exporting activities (Export) as a dichotomous variable measuring the share of total sales sold abroad in 2009. Exporting can have a positive impact on cooperation, given that exporters potentially have a larger network of cooperation partners than do non-exporting firms. Furthermore, exporting firms might have more incentive to innovate as a result of competitive pressure on international markets and thus be more likely to self-select into public support programmes (Busom and Fernández-Ribas 2008; Cerulli and Potí 2012; Czarnitzki and LopesBento 2013). In addition, the model includes the variable measuring competitive pressure (Competition), which is equal to 1 if firms responded 'Very strong' to the question: 'How would you judge the competition in your main market(s)?', and 0 otherwise. According to Garcia and Mohnen (2010), firms facing a higher degree of competition could be more likely to need public support. 
In addition, to control for otherwise unobserved sources of firm heterogeneity that are associated with industry characteristics, we include sectoral dummy variables for all six industries of interest: automotive; ceramics; leather; metallurgy; textile; and food processing. The base category is other traditional manufacturing industries. Likewise, to control for otherwise unobserved sources of firm heterogeneity that are associated with country (region) characteristics, the model includes six country/region dummy variables for Germany, Italy, France, Portugal, Spain and the Netherlands (with the UK being the base category).

One limitation of our specification reflects our data, which constrains the analysis to cross-sectional differences, whereas longitudinal and cross-country survey data to analyse differences in cooperation or to control for lagged cooperation would be preferable. Unfortunately, to our knowledge, no such data for SMEs in traditional manufacturing industries exists. ${ }^{8}$ Yet there is a concern that, because we are unable to control for previous cooperation, reverse causality may be important; namely, instead of or as well as public funding inducing firms to change their cooperation behaviour, it may be the case that firms with a history of cooperation are more likely to apply for funding. ${ }^{9}$ While our dataset does not include previous cooperation, it does include a question designed to investigate a variety of SME needs to facilitate participation in innovation support programmes, one of which is 'Adequate networks of potential partners'. Seventy-four firms responded that the availability of such networks was either of 'no importance' or 'low importance' to participation in support programmes and so, by implication, evinced established cooperative behaviour independently of programme participation. From these responses, we derived a variable Well_networked. In our sample, $24 \%$ of firms that did not participate in support programmes were 'well networked' and $26 \%$ of firms that did participate, a difference that is not statistically different from 0 ( $p=$ 0.68 in a standard $t$ test). Moreover, when added as a regressor to the model reported in the next section, the Well_networked variable did not prove to be a significant predictor of programme participation (with a $t$ statistic of below 1) and did not improve the quality of

\footnotetext{
${ }^{8}$ However, a single-country study for Spain using the Survey of Business Strategies (known by the Spanish initials ESEE) would enable panel analysis but without the full range of cooperative partners considered in the present study.

${ }^{9}$ We thank an anonymous referee for this point.
}

matching. This evidence that prior networking and, hence, established cooperative behaviour did not exert any discernible influence on the propensity to participate in innovation support programmes goes some way to allay concerns that the findings reported below may reflect reverse causation rather than programme effects.

Our dataset also provides direct information on respondents' subjective perceptions of the impact of support measures that supports a causal interpretation of our econometric estimates. The survey included the following question: 'For the first support measure ... which were the impacts from your participation on ...?' The same question was presented also for a second support measure, where applicable. Twenty potential impacts were listed, including three (arguably four) directly pertaining to cooperation: 'Formation of new partnerships and networks'; 'Improved R\&D linkages with universities and research institutes'; 'Improved R\&D linkages with other business organisations'; and (arguably) 'Improved commercial linkages with other organisations'. These responses can play no role in our econometric analysis, since they exist only for programme participants ('treated' firms). However, they are informative about what respondents believe to have been the influence of support measures on cooperation. In Table 1, the rows give short forms of the four impacts listed above and the columns record the responses. For comparison, and to demonstrate that the respondents discriminated between impacts in their responses, we add two more impacts: on 'Speed of completion of the innovation project' (the third highest impact for the first support measure and the highest for the second) and on 'Safety and environmental certification' (the lowest impact in both cases).

Seventy-four per cent of respondents attribute at least some degree of importance to their first support measure in promoting the 'Formation of new partnerships and networks' (the sum of 'Low' importance, 'Important', 'High' and 'Very high' importance as a percentage of 123). Seventy percent respond similarly for each of the other three types of cooperation. In comparison, 'Speed of completion of the innovation project' was so identified by $85 \%$ and 'Safety and environmental certification' by only $41 \%$ of respondents. For the smaller number of firms having received a second support measure, the comparison is similar: new partnerships and networks, $77 \%(n=61)$; speed of completion, $84 \%(n=$ $62)$; and safety and environmental certification $46 \%$ $(n=59)$. 
Table 1 Respondents' perceptions of the impact of support measures

\begin{tabular}{|c|c|c|c|c|c|}
\hline \multirow[t]{2}{*}{ Impact of support measure 1 on: } & \multicolumn{5}{|c|}{ Degrees of importance (frequency of responses) } \\
\hline & No & Low & Important & High & Very high \\
\hline External relationships $(n=123)$ & 32 & 31 & 24 & 21 & 15 \\
\hline R\&D linkages (universities, etc.) $(n=125)$ & 38 & 25 & 26 & 21 & 15 \\
\hline R\&D linkages (other businesses) $(n=122)$ & 36 & 32 & 29 & 18 & 7 \\
\hline Commercial linkages $(n=120)$ & 36 & 31 & 28 & 18 & 7 \\
\hline Speed of completion $(n=124)$ & 19 & 15 & 39 & 32 & 19 \\
\hline Safety and environmental certification $(n=123)$ & 72 & 21 & 23 & 5 & 2 \\
\hline
\end{tabular}

Source: Calculated from the GPrix database (GPrix Deliverable 1.7-impact assessment of measures on SMEs; GPrix Deliverable 3.3-Recommendations Report; http://www.gprix.eu/)

The evidence available in our dataset is consistent in going some way to allay concerns that the findings reported below may reflect reverse causation rather than programme effects: first, evidence-admittedly weak - that prior networking and, hence, established cooperative behaviour did not exert any discernible influence on the propensity to participate in innovation support programmes; and, second, direct-albeit subjective-evidence that innovation support measures promote cooperation. Moreover, the sensitivity analysis reported below adds some reassurance that the estimated treatment effects are not driven by unobserved heterogeneity.

\section{Results and discussion of the empirical analysis}

\subsection{Results}

The propensity score was estimated by a logit model, which is the most frequently used model in this line of research (Herrera and Nieto 2008). The results are reported in Table 2. The results indicate a statistically significant positive effect of exporting $(p=0.071)$ on programme participation together with two positive country effects (Spain $-p=0.000$ and Germany $-p=0.013$ ) and one negative industry effect (Food processing $-p=0.081$ ). However, in the matching approach, the main focus is not on the estimated coefficients but rather on whether covariates between matched pairs of treated and untreated firms are balanced given the estimated propensity scores. The literature on matching suggests the inclusion of even those covariates that are statistically insignificant, because their inclusion does not increase bias in subsequent matching estimations (Millimet and Tchernis 2009). Moreover, our study is limited by a lack of information on the selection process, which means that the largest possible number of covariates should be modelled in the estimation of the propensity score (Millimet and Tchernis 2009; Steiner et al. 2010).

The algorithm by Becker and Ichino (2002) indicated satisfactory balancing properties of the estimated propensity scores. Moreover, few observations are lost due to the common support restriction, which indicates a large overlap of estimated propensity scores among subsidised and non-subsidised SMEs. ${ }^{10}$

Table 3 presents the estimated ATT effects. These are fairly consistent across the three matching estimators. Accordingly, we interpret the mean effects for each type of cooperative partner.

\subsection{Discussion}

Table 3 reports a positive but heterogeneous impact of public support on SME cooperation for innovation. In addition to reporting the estimated ATTs, we also test for unobserved heterogeneity. Although no previous study on behavioural additionality reports sensitivity analysis with respect to 'hidden bias', the evaluation literature suggests this as a complement to propensity score analysis, because the assumption on unconfoundedness cannot be tested directly (Nannicini 2007; Caliendo and Kopeinig 2008; Ichino et al. 2008; Guo and Fraser

\footnotetext{
${ }^{10}$ These results are available on request.
} 
Table 2 Results of logit estimation. Dependent variable: participation in public support programmes in the period 2005-2009

\begin{tabular}{ll}
\hline Variables & Coefficient (standard error) \\
\hline Size & $-0.003(0.003)$ \\
Competition & $-0.202(0.311)$ \\
Export & $0.008^{*}(0.004)$ \\
Spain & $1.965^{* * *}(0.507)$ \\
France & $0.660(0.467)$ \\
Germany & $1.184 * *(0.479)$ \\
Italy & $0.306(0.432)$ \\
Netherlands & $0.287(0.479)$ \\
Portugal & $0.744(0.588)$ \\
Leather & $-0.663(0.732)$ \\
Ceramics & $-0.132(0.559)$ \\
Textile & $-0.604(0.481)$ \\
Mechanical/metallurgy & $0.362(0.358)$ \\
Automotive & $0.106(0.509)$ \\
Food processing & $-0.888^{*}(0.509)$ \\
Constant & $-0.772 * *(0.364)$ \\
No of obs. & 295 \\
Log-likelihood & -187.054 \\
Pseudo $R^{2}$ & 0.079 \\
\hline Notes: & \\
\hline$* 0.01 * * 0<05 * 0<$ & 0.10
\end{tabular}

Notes: $* * * p<0.01, * * p<0.05, * p<0.10$

2010). In this study, we apply two types of sensitivity analysis. The simulation-based approach (kernel matching with replacement) augments the propensity score model with a simulated measure of unobserved heterogeneity; if the resulting simulated ATT (Table 3, column 5) is close to the ATT estimated under the CIA (column 2), then the estimate is likely to be robust to unobserved heterogeneity (Becker and Caliendo 2007; Nannicini 2007; Ichino et al. 2008). Alternatively, the Rosenbaum bounding approach (NN matching without replacement) determines how large the impact of an unobserved variable has to be to render the treatment effect statistically insignificant, under the assumption that this variable simultaneously affects both treatment assignment and the outcome variable (Rosenbaum 2002; DiPrete and Gangl 2004); this approach provides the two Mantel and Haenszel (1959) test statistics, one to test for over-estimation of the treatment effect when unobserved heterogeneity is suspected and the other to test for under-estimation (Becker and Caliendo 2007). These results of the Rosenbaum approach are reported in Table 3, column 6 (the full results are available on request).
We now relate the estimated ATTs to our four hypotheses. Hypothesis 1 is weakly supported: public support has a positive impact on vertical cooperation with customers and suppliers. However, of the types of cooperation significantly promoted by public support, the impact on vertical cooperation is the smallest: the mean ATT for cooperation with suppliers suggests an increased probability of cooperation of 11.4 percentage points (pp) and for cooperation with customers of $10.4 \mathrm{pp}$. From the perspective of statistical significance, these estimates are not fully robust. Nonetheless, these estimates may be economically plausible. Because cooperation along the supply chain between partners with complementary competencies is well established in the 'innovation model' of manufacturing SMEs, there may be only a minimal role at the margin for public support in promoting such cooperation in the sample regions (which are all from developed market economies).

Hypothesis 2 is supported in part. We hypothesised a 'small' effect of public support in promoting cooperation with competitors relative to other forms of cooperation. Yet, we find that public support is ineffective in promoting cooperation with competitors, whereas it is effective - albeit in varying degrees - in promoting all other types of cooperation. In no case is the estimated ATT significantly different from 0 , a finding supported by both sensitivity tests. According to Clarysse et al. (2009), with respect to the types of cooperative partners, the risk of cooperation failure is particularly high for cooperation with competitors, and our results suggest that innovation policy instruments might not be able to mitigate this risk. These suggestions from the literature may apply with even greater force to SMEs in traditional manufacturing.

Our estimates uniformly support the two hypotheses relating to knowledge providers. In line with Hypothesis 3, the impact of public support is on average to increase the probability of partnerships with private sector consultants by $21.2 \mathrm{pp}$. Moreover, while this effect is about the same as the effect on cooperation with government research centres and public research centres, this effect is less than the impact on cooperation with HEIs (the $95 \%$ confidence intervals of the respective ATT estimates do not overlap). These findings are supported by both sensitivity tests: the first confirms the level of statistical significance and the second suggests no bias 


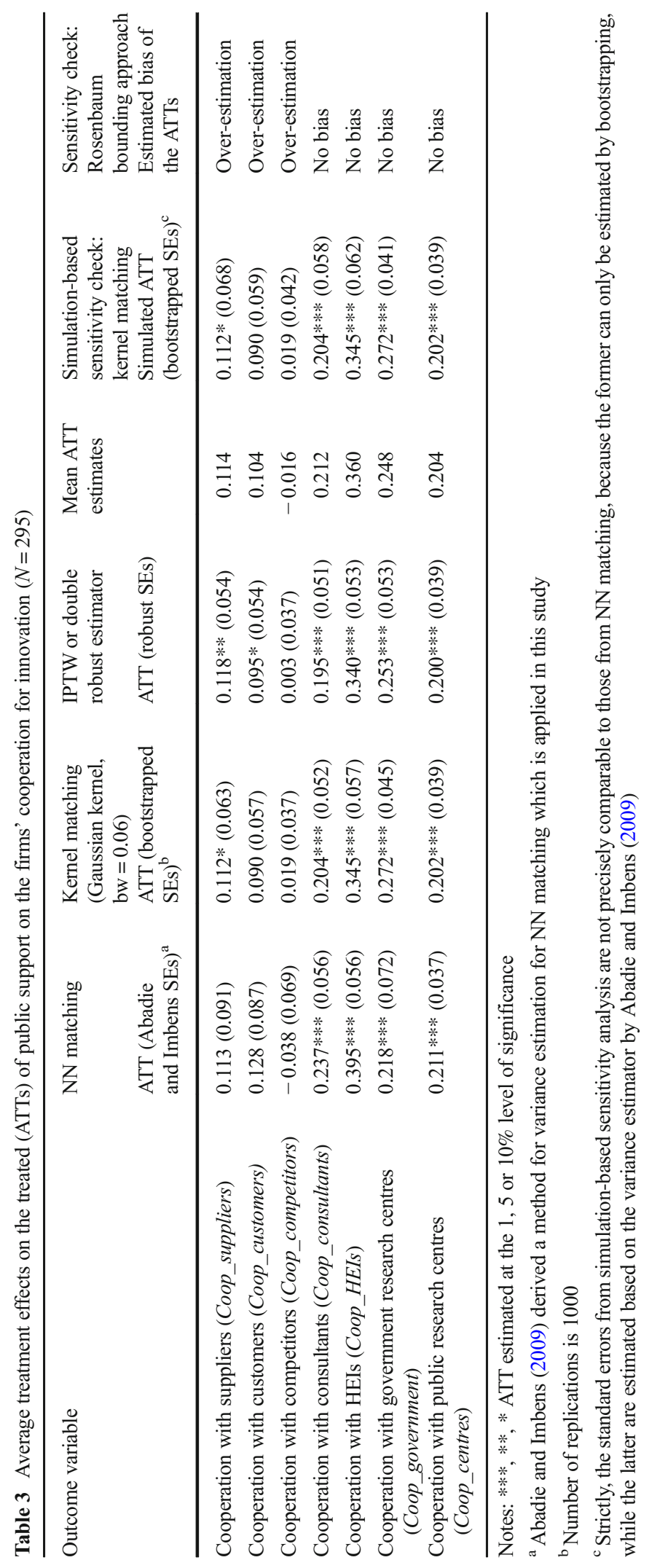


in the estimate. Finally, in line with Hypothesis 4, the effects of public support on the three types of cooperation described as public-private partnerships are all positive and uniformly significant at the $1 \%$ level and are all supported by both sensitivity tests. Moreover, each of the three types of cooperationwith HEIs, government research centres and public research centres - responds more to public support than does any other type of cooperation: on average, treatment assignment increases the probability of cooperating with HEIs by $36.0 \mathrm{pp}$; of cooperating with government research centres by $24.8 \mathrm{pp}$; and of cooperating with public research centres by 20.4 pp. Following the discussion in Section 3.2, acquiring external knowledge through cooperation could be subject to cooperation failure. In this case, increased cooperation with public institutions may be facilitated by greater trust insofar as these institutions are unlikely to appropriate a firm's intellectual property.

This heterogeneous effectiveness may be instructive for policy makers: the induced behavioural impact of participation in public innovation support programmes on SME cooperation with external knowledge providers is relatively great; the impact on vertical cooperation is relatively limited; and the lack of any discernible impact on horizontal cooperation may reflect insuperable barriers to such cooperation for manufacturing SMEs. These findings suggest that the broad range of innovation support programmes has the effect-whether intended or unintended - of promoting the firms' cooperation. Coupled with our suggestion of cumulative causation between firms' behaviour and emergent system effects (in Section 3.1 above), these findings also suggest a channel through which public policy can contribute to the consolidation and extension of innovation ecosystems.

\subsection{Heterogeneous effects of public funding}

In this section, we investigate whether or not and, if so, to what extent the effects of public funding on cooperation for innovation differ across countries, industries, sources of funding and firm size categories. The number of observations precludes separate estimation by country and industry but proved sufficient to enable separate estimates to be obtained for different sources of funding and firm size categories.
We investigate heterogeneity by industries and countries to check whether or not our findings have external validity (i.e. whether or not they may reasonably be used to inform policy in different industries and countries). To this end, we use a two-step approach $^{11}$ : first, we regress the estimated treatment effects on industry and country dummies together with firm-level characteristics that may be associated with heterogeneous effects; then we conduct separate matching analysis after excluding countries or industries displaying significant effects. Appendix Table 9 reports OLS regressions on the ATTs from 'any type of cooperation' on two sets of variables: first, the same variables as appear in the logit model (Table 2); and, as a robustness check, this specification augmented with additional variables (namely, dummy variables for categories of innovative sales as a proportion of turnover; types of innovationproduct, process, organisational and marketing; and membership of an enterprise group). The same procedure was repeated for each of our seven cooperation outcome variables (these results are not reported but are available on-line in a Stata $\log$ file; see footnote 3 above). Each of the resulting 16 regressions was estimated with robust standard errors, is well specified with respect to functional form (according to the Ramsey test) and shows no signs of excessive multicollinearity (according to the mean variable inflation factors). Table 4 give a qualitative summary of the estimates of interest, reporting the industry and country dummies significant at the conventional $5 \%$ level: $+(-)$ indicates positive (negative) and significant; 0 indicates a nonsignificant estimate; and blank cells signify statistically insignificant effects from both models.

From 48 possibilities among the industries, five robustly reveal heterogeneity in our estimated effects (i.e. proving to be statistically significant and positive or negative in both models). Three of these reveal heterogeneities in the effect of programme participation on cooperation with customers, although we interpret the uniformly positive significant estimates for five of the industries to be suggesting that the auto industry has more in common with the omitted 'other industries' category than with the other traditional industries in this respect. The other two reveal heterogeneities in the effect of

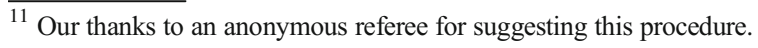


Table 4 Industry and country heterogeneities in the results reported in Table 3

\begin{tabular}{|c|c|c|c|c|c|c|c|}
\hline \multirow[t]{2}{*}{ Outcome variables } & \multicolumn{4}{|c|}{ Industries } & \multicolumn{3}{|l|}{ Countries } \\
\hline & $\begin{array}{l}\text { Leather } \\
\text { Small m }\end{array}$ & $\begin{array}{l}\text { Ceramic Textile } \\
\text { odel/large model }\end{array}$ & Mechanical Auto & Food & Spain France & Germany Italy Netherlands & Portugal \\
\hline Aggregate cooperation & & & & & $0 /+$ & & \\
\hline Suppliers & & & & & & $-1-$ & \\
\hline Customers & $+/ 0$ & $+/+$ & $+/+$ & $+/ 0$ & $-/ 0$ & & \\
\hline Competitors & & & & & & $-1-$ & \\
\hline Consultants & $-1-$ & & & $-1-$ & $+/+$ & & \\
\hline HEIs & $0 /-$ & & $+/ 0$ & & $+/+$ & & \\
\hline Government & & & & & $+/+$ & & \\
\hline Public research centres & & & & & $+/+$ & $+/ 0$ & \\
\hline
\end{tabular}

programme participation on cooperation with consultants. In addition, we note possible heterogeneity in cooperation with HEIs. We do not have sufficient observations to robustness check our matching estimates reported in Table 3 for particular industries (see Appendix Table 8 for the proportions of the sample accounted for by each industry and country). Instead, step 2 of our procedure is to omit industries from the sample where these are potential sources of heterogeneity to assess the extent to which Table 3 estimates are driven by industry outliers:

1. For cooperation with customers, omitting 'auto'

2. For cooperation with consultants omitting 'leather' and 'food'

3. For cooperation with HEIs omitting 'leather' and 'mechanical'

From 48 possibilities among the countries, six robustly reveal heterogeneity in our estimated effects. The two associated with Germany both concern particular types of cooperation with other firms (suppliers and competitors) but not with knowledge providers. Conversely, we have evidence of heterogeneity associated with Spain in each category of cooperation with knowledge providers as well as the only evidence of heterogeneity in the effect of programme participation on cooperation generally (aggregate cooperation). Accordingly, we omit countries to assess the extent to which Table 3 estimates are driven by country outliers:

1. For both cooperation with suppliers and cooperation with competitors, omitting Germany
2. For cooperation with each of the four types of knowledge provider, omitting Spain

Robustness checking for the effects of industry and country outliers gives rise to three and six new ATT estimates, respectively. These are reported in Table 5, together with the full sample estimates from Table 3 for ease of comparison.

There is no evidence that our matching estimates are driven by industry heterogeneity. Although the effect of programme participation on cooperation with customers gains statistical significance, the size of the estimate is little changed and, in all respects, is very close to the double robust estimate reported in Table $3(0.095$, also significant at the $10 \%$ level). Lack of industry heterogeneity is consistent with our argument in Section 2 that the traditional manufacturing industries constitute a coherenthence, homogeneous - unit of analysis. Among the country estimates, only one reveals substantial change: the effect of programme participation on cooperation with government research centres collapses in size and loses statistical significance once Spain is omitted from the sample. Otherwise, country heterogeneity makes little noteworthy difference to estimated programme effects on cooperation with consultants and HEIs; moreover, although the size of the effect on cooperation with public research centres is notably reduced, the full sample and the reduced sample estimates are statistically different only at the $1 \%$ level $(p=0.033)$. We conclude that Table 3 estimates are not unduly driven by industry or country outliers. 


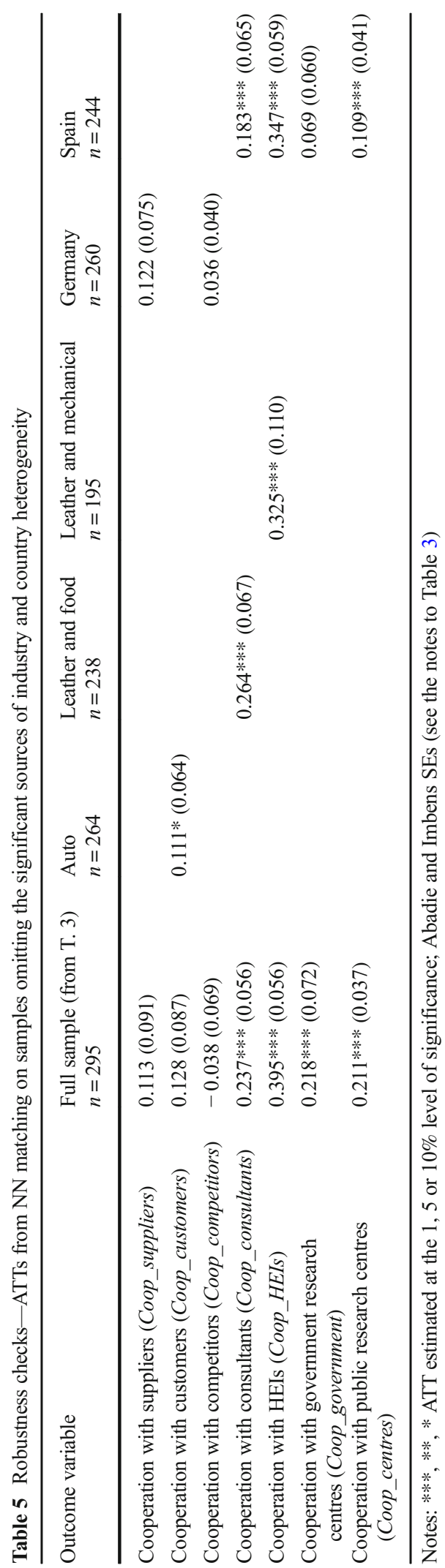

Table 6 reports estimates from our preferred NN matching approach (Table 3) of the effects of public funding by sources of funding and according to firm size. For ease of comparison, column 1 reproduces the estimates from all sources reported in Table 3. Separate investigation of support from national sources (including local or regional sources) and from the EU reveals some evidence that public support from both sources promotes cooperation with suppliers (comparing columns 2 and 3 with column 1), while only national support promotes cooperation with customers (column 2). As expected, in contrast to the effects of EU support, national support promotes cooperation with government and other (nationally based) public research institutions. Yet both national and EU support promote cooperation with other knowledge suppliers (consultants and HEIs).

Turning to our estimated effects disaggregated by firm size (columns 4, 5 and 6), our previous finding of weak effects on inter-firm cooperation is qualified by evidence of positive effects on cooperation with suppliers among small firms and on both cooperation with customers and cooperation with competitors among medium firms. However, such effects are not systematic. The evidence on cooperation with knowledge providers is also qualified, although only a little. Although the effects of public support on cooperation with government and other (nationally based) public research institutions remain systematic - uniformly substantial and significant across firm sizes - the evidence on cooperation with consultants and HEIs remains strong only for micro and small firms (although because these effects for medium firms are so imprecisely estimated, the $95 \%$ confidence intervals - not reported-overlap with the estimates for micro and small firms). However, in spite of this additional evidence on the heterogeneity of public support effects on cooperation across firms of different size, we can still conclude that the weight of our evidence suggests a more systematic impact of public support on cooperation with knowledge providers than on cooperation with suppliers, customers or competitors.

We concluded Section 6.1 by suggesting that public innovation support programmes promote firms' cooperative behaviour and thus contribute to the consolidation and extension of innovation ecosystems. The evidence presented in this section provides some tentative guidance on the effective allocation of public support. First, only national support promotes cooperation between 


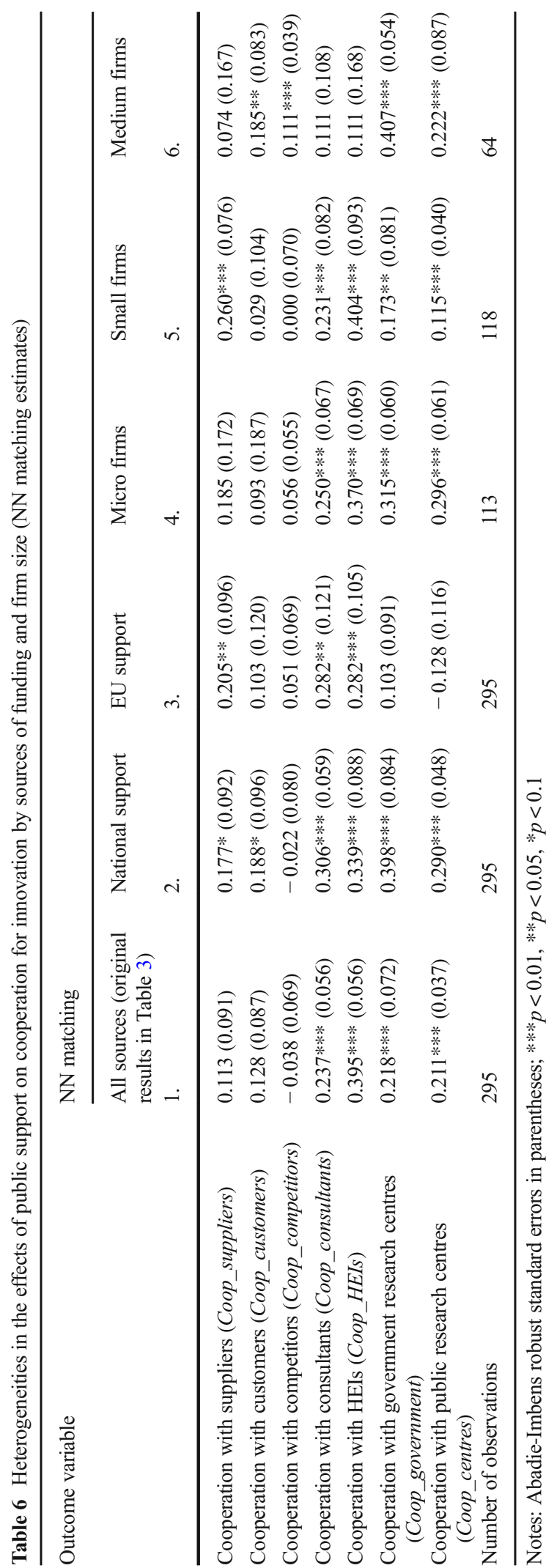

firms and national research centres (government and public in Table 6), while either EU or national support is effective in promoting cooperation with both consultants and HEIs. Second, public support promotes cooperation between firms of all sizes and national research centres, while public support for micro and small firms most effectively promotes cooperation with consultants and HEIs. Conversely, support for medium firms may do more to promote inter-firm cooperation.

\section{Conclusion}

Following a statement of our main findings, we conclude by considering: (i) different dimensions of heterogeneity in our findings and their implications for policymaking; (ii) the contribution of our findings to the understanding of SME innovation ecosystems in traditional manufacturing industry; (iii) the implications of our findings for the promotion of incremental innovation in traditional manufacturing industry; and (iv) the implications of our findings for the evaluation of public innovation support programmes. Finally, we consider the limitations of this study.

By applying matching methods to estimate ATT effects, we find that innovation support programmes for SMEs in traditional manufacturing sectors do not promote cooperation with competitors, marginally promote cooperation with customers and suppliers and strongly promote cooperation with external knowledge providers, i.e. private sector consultants, government research centres, public research centres and HEIs. These findings are similar to the effects previously reported in the literature for other sectors.

Further, we explore potential heterogeneities in the effects of public support with respect to countries, industries, sources of funding and firm size categories. In our sample, industry heterogeneity does not unduly affect our estimates, which is consistent with our argument that traditional manufacturing industry is a coherent unit of analysis. Moreover, noteworthy country heterogeneity is limited to the findings that upon omitting the Spanish observations (i) the estimated effect of public support on cooperation with government research centres loses statistical significance and (ii) the estimated effect on cooperation with public research centreswhile remaining substantial and statistically significant - approximately halves. These robustness checks suggest that our results have external validity within the 
domain of SMEs in traditional manufacturing industry and, so within this domain, may reasonably be used to inform policy on public support. Nonetheless, we cannot be definitive, as our dataset has too few observations to permit separate estimation by industry and country. Accordingly, policy makers should always be alert to the possibility of country and industry variations.

Sources of funding are associated with some noteworthy heterogeneities. National support promotes cooperation with government and other (nationally based) public research institutions, although the former finding may be unduly influenced by the Spanish observations. Conversely, both national and EU support promote cooperation with consultants and HEIs, which is a typical objective of EU support. Finally, although the effects of public support on cooperation with government and other (nationally based) public research institutions remain uniformly substantial and significant across firm sizes, the evidence on cooperation with consultants and HEIs remains strong only for micro and small firms. However, the weight of our evidence still suggests a more systematic impact of public support on cooperation with knowledge providers than on inter-firm cooperation.

Our findings make a twofold contribution to knowledge on the potential role of public policy in supporting the development of innovation ecosystems. On the one hand, in Section 3.1, we argue that cooperation by firms with other firms and related institutions gives rise to emergent system properties that positively feedback onto firm-level cooperation for innovation. In the presence of this cumulative causation effect, our findings not only provide evidence for a direct influence of public policy on firms' cooperative behaviour but also suggest an indirect influence via support for the wellfunctioning of the wider innovation ecosystem. On the other hand, our findings are consistent with the market emphasis of the innovation ecosystems literature in suggesting that the role of public policy may be less related to the creation of innovation ecosystems and much more to do with their well-functioning and consolidation. At the inception of the firms' innovation ecosystems are their relationships with other firms. In this paper, we report economically small and by no means uniformly statistically significant positive effects of public innovation support programmes on cooperation with either suppliers or customers, and only one estimate suggesting that such programmes promote cooperation with competitors. In contrast, we report mainly statistically significant and economically substantial effects of public innovation support programmes on cooperation with both private and public sector knowledge providers. In conclusion, public innovation support programmes can assist SMEs in traditional manufacturing industry to consolidate and/or extend their innovation ecosystems beyond the more familiar partners of suppliers, customers - and, possibly, competitors - by promoting cooperation with a range of knowledge providers. Accordingly, in this case, we characterise the role of public policy as systems conforming rather than systems creating. Because of heterogeneity among ecosystems (Brown and Mason 2017), we cannot offer this conclusion as generally applicable. However, we argue that public policies promoting cooperation for innovation by SMEs may be particularly effective in traditional manufacturing industries, because such public support may contribute to offsetting the loss of systemic benefits arising from deindustrialisation and the associated thinning out of supply chains and supporting institutions.

Previous studies have associated behavioural additionality most strongly with radical innovation. Afcha Chàvez (2011) argues that this is particularly the case with respect to cooperation with universities and public research organisations. Given our argument that SMEs in traditional manufacturing industries carry out mainly incremental innovation, then our findings not only extend knowledge about SME cooperation to a previously neglected but important sector of manufacturing industry but also to a somewhat neglected but important type of innovation. The evidence reported in this study suggests that innovation support programmes induce cooperative behaviour by SMEs in traditional manufacturing industries performing incremental innovation. This is consistent with Clarysse et al. (2009) who report larger behavioural additionality for less R\&D intensive SMEs than for highly R\&D intensive large firms. The corollary is that innovation support for SMEs in traditional manufacturing industries may have been provided at below the socially optimum level. Our findings extend the range of contexts in which policy makers should emphasise measures designed to attenuate cooperation failures (Zeng et al. 2010).

Our findings also have major implications for the evaluation of innovation support programmes. A previous evaluation of the effects of innovation support programmes using the same data as this study [Radicic et al. 2016] reports output additionality. However, the 
present study suggests that focussing only on innovation output effects in a cross-sectional context neglects induced cooperation effects, which unfold over time with further positive effects on innovation. We argue that these dynamic effects may arise for two reasons. First, induced cooperation between firms and complementary institutions contributes to the wider innovation ecosystem, which in turn positively influences firms' cooperation and innovation behaviour. If these induced or feedback effects from improved functioning of firms' innovation ecosystems are not accounted for by evaluation studies, then the findings of evaluation studies may be negatively biased. Second, within firms, behavioural additionality is also likely to induce further output additionality (Davenport et al. 1998). [Radicic et al. 2016] find output additionality from innovation support programmes and the present study finds positive cooperation effects. Together, these studies question Georghiou (2002) who argues that input and/or output additionality and behavioural additionality are substitutable, and provide support for Clarysse et al. (2009) who argue that they are complementary. In turn, complementarity suggests a positive feedback process for SMEs in traditional manufacturing industry: public innovation support programmes lead directly to input and/or output additionality and indirectly to (induced) cooperation (behavioural additionality) which, in turn, gives rise to further input and/or output additionality.

To investigate the dynamics of these two hypothesised processes will require the study of rich longitudinal data. However, even in the absence of such empirical investigation, the proposed dynamic linkage between support, innovation and cooperative effects leading to second-round innovation effects (... and so on) suggests that the output additionality among SMEs in traditional manufacturing industries reported in [Radicic et al. 2016] - as well as by other studies for other sectors and for different types of firm - might be underestimated. We conclude that once we take into account that the effects of programmes targeting innovation outputs may operate both directly and indirectly over time (both between and within firms), then the estimated effects are likely to be larger and the case for policy support stronger. This will be the case even using current datasets and methods, as this study demonstrates. A corollary is that evaluation studies of innovation support programmes for SMEs should be designed to capture not only input and/or output additionality but also behavioural and systemic effects.
This study has limitations that remain to be addressed. The first is reverse causality. Within the limitations of our cross-section dataset, we are unable to control for unobserved heterogeneity, in particular with respect to previous cooperative behaviour. Hence, we are concerned that continually cooperating firms are more likely to apply for funding, in which case public funding may be wrongly identified as a cause of cooperation behaviour. Our survey data provides some evidence consistent with programme effects rather than reverse causation, and sensitivity analysis adds some reassurance that the estimated treatment effects are not driven by unobserved heterogeneity. Nonetheless, while we have gone as far as our data and current techniques permit, we acknowledge that we cannot be definitive with regard to causation. Accordingly, advances in both respects are among our suggestions for further research. The second limitation concerns the extent of external validity. Investigation of industry and country heterogeneities leads us to conclude that the traditional manufacturing industries constitute a coherent unit of analysis and that country heterogeneity is minimal. Nonetheless, in the absence of sufficient observations to estimate cooperation effects separately by industry and country, we cannot conclude definitively that we have fully accounted for industry and country biases. While our results may reasonably be used to inform policy on public support for SMEs in traditional manufacturing industries in developed market economies, policy makers should always be alert to the possibility of country and industry variations. Additional limitations may be acknowledged in brief: (a) available data does not allow assessment of the effectiveness of public support on other types of behavioural additionality, such as cognitive capacity additionality (Fier et al. 2006; Busom and Fernández-Ribas 2008); (b) crosssectional data precludes exploration of the medium- to long-run programme effects on cooperative behaviour (Busom and Fernández-Ribas 2008); and (c) it would be informative to explore whether additionality of a support programme would be affected by the breadth of cooperative partnerships.

Funding information This research benefitted from the European Commission, FP7-SME-2009-1; Grant Number: 245459 (http://business.staffs.ac.uk/gprix/en/index.htm/): Which support measures can help regions based on traditional industries to prosper in the knowledge economy? 


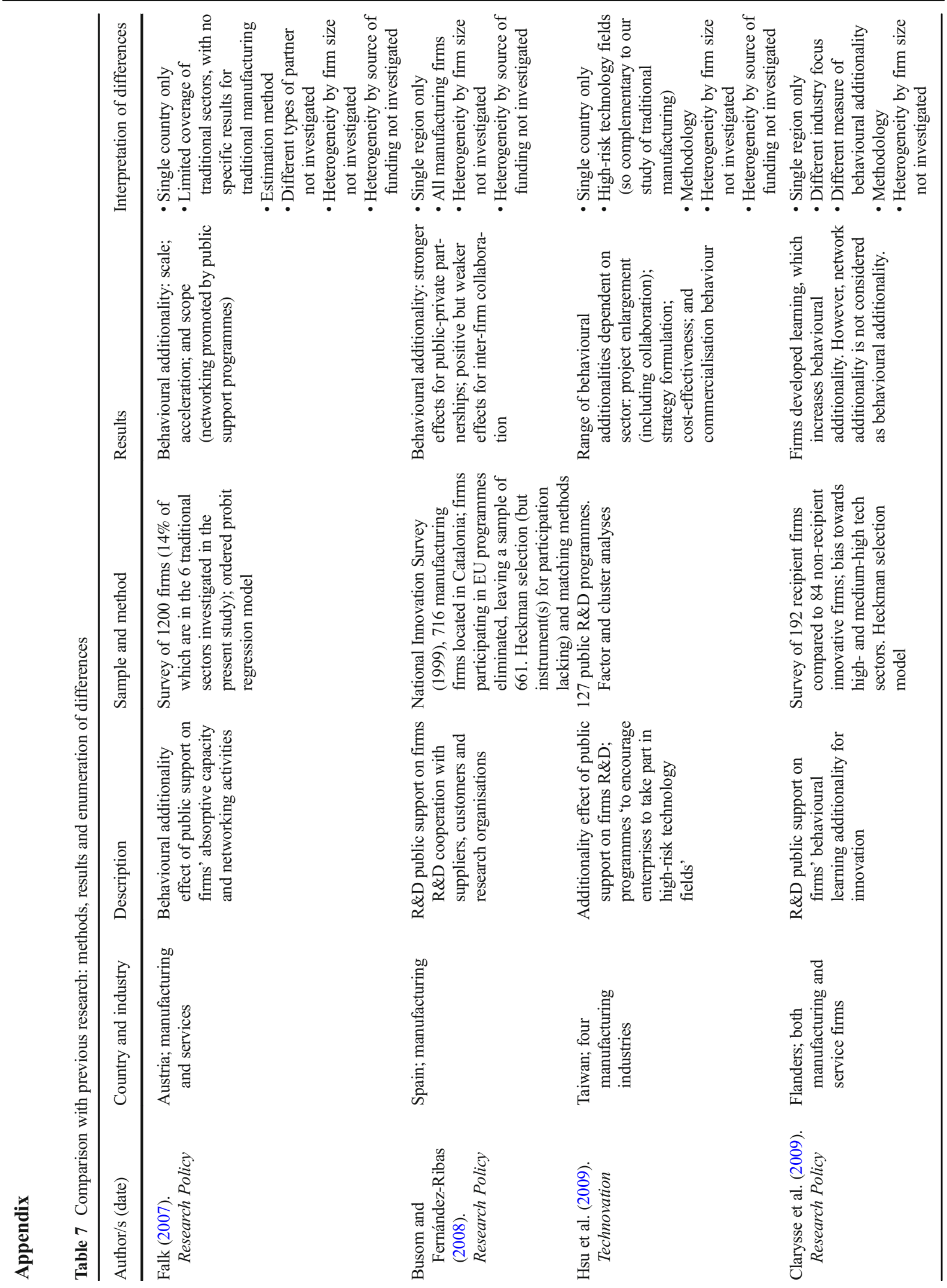




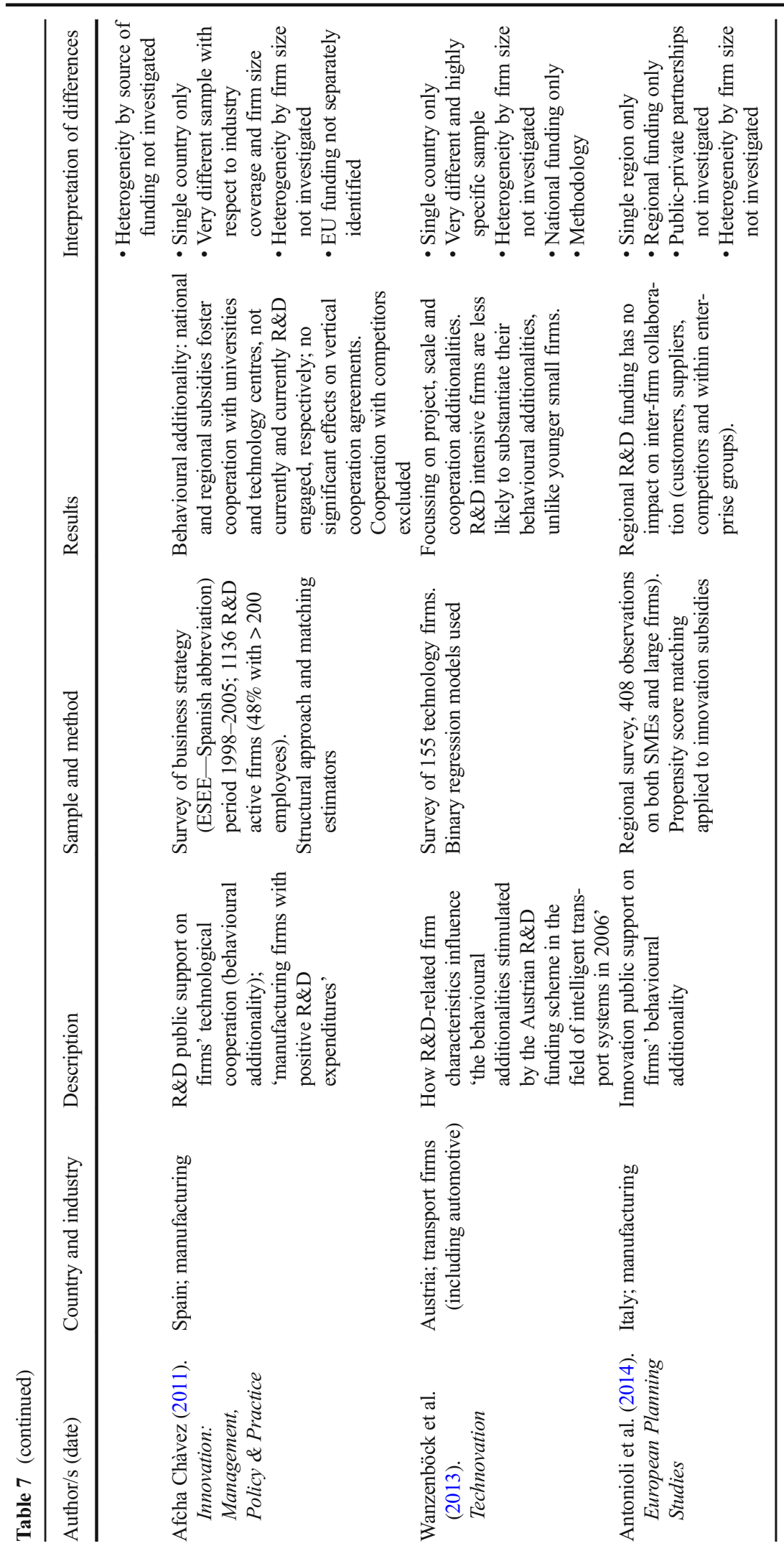




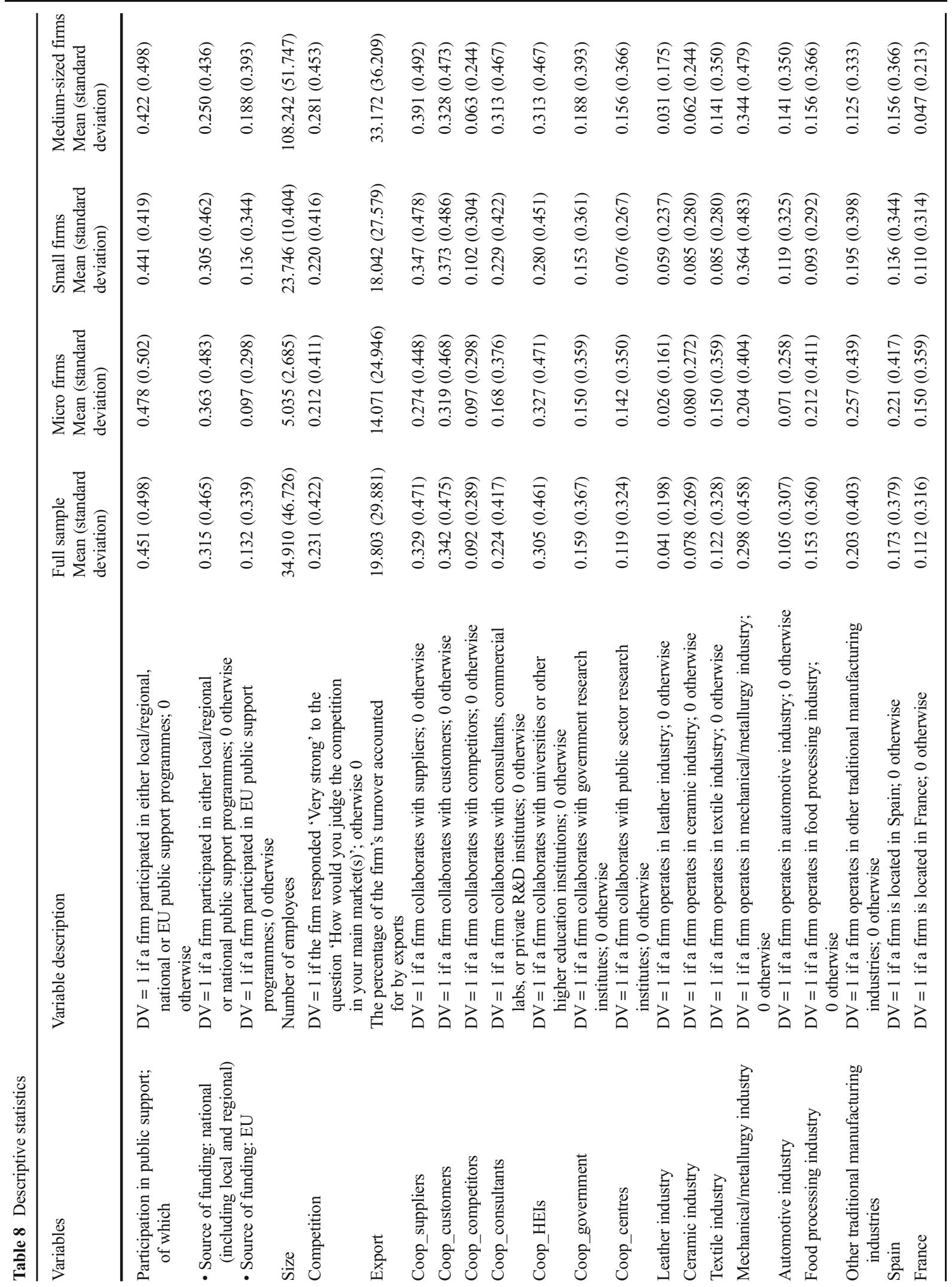




\begin{tabular}{|c|c|c|c|c|c|c|}
\hline \multirow{2}{*}{ 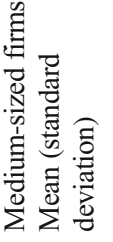 } & \multirow{2}{*}{ 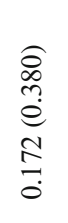 } & \multirow{2}{*}{ 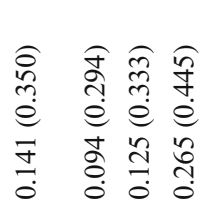 } & & \multicolumn{3}{|c|}{$\begin{array}{l}\text { Table } 9 \text { OLS regression of firm-level treatment effects on indus- } \\
\text { tries, countries and firm-level characteristics. Dependent variable: } \\
\text { GenCoop-ATTs from any type of cooperation }\end{array}$} \\
\hline & & & & Variables & $\begin{array}{l}\text { Coeff. (robust } \\
\text { SEs) }\end{array}$ & $\begin{array}{l}\text { Coeff. (robust } \\
\text { SEs) }\end{array}$ \\
\hline \multirow{5}{*}{ 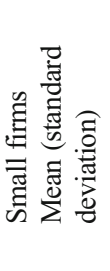 } & \multirow{5}{*}{ 过 } & \multirow{5}{*}{ 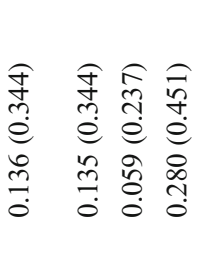 } & & $\begin{array}{l}\text { Size (number of } \\
\text { employees) }\end{array}$ & $-0.000(0.001)$ & $0.000(0.001)$ \\
\hline & & & & Leather industry & $0.174(0.182)$ & $0.059(0.203)$ \\
\hline & & & & Ceramics industry & $0.055(0.147)$ & $0.044(0.154)$ \\
\hline & & & & Textile industry & $0.213 *(0.128)$ & $0.192(0.136)$ \\
\hline & & & & $\begin{array}{l}\text { Mechanical/metallurgy } \\
\text { industry }\end{array}$ & $0.108(0.106)$ & $0.049(0.116)$ \\
\hline \multirow{5}{*}{ 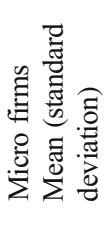 } & \multirow{5}{*}{ 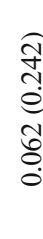 } & \multirow{5}{*}{ 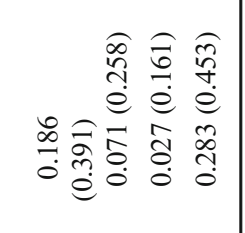 } & & Automotive industry & $0.118(0.151)$ & $0.181(0.159)$ \\
\hline & & & & Food processing industry & $-0.056(0.124)$ & $-0.101(0.141)$ \\
\hline & & & & $\begin{array}{l}\text { Competition (in } \\
\text { product markets) }\end{array}$ & $-0.017(0.086)$ & $-0.098(0.088)$ \\
\hline & & & & Spain & $0.222 *(0.120)$ & $0.263 * *(0.124)$ \\
\hline & & & 惐 & France & $-0.143(0.146)$ & $-0.043(0.141)$ \\
\hline \multirow{5}{*}{ 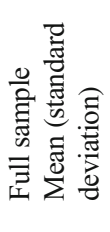 } & \multirow{5}{*}{ 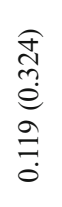 } & \multirow{5}{*}{ 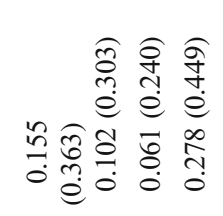 } & 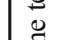 & Germany & $0.088(0.130)$ & $0.232(0.150)$ \\
\hline & & & $\stackrel{F}{\Xi}$ & Italy & $0.042(0.115)$ & $0.173(0.126)$ \\
\hline & & & ల & Netherlands & $-0.222(0.166)$ & $-0.214(0.166)$ \\
\hline & & & 50 & Portugal & $-0.056(0.166)$ & $-0.051(0.173)$ \\
\hline & & & قू & Exports & $-0.003 * *(0.001)$ & $-0.003 * *(0.001)$ \\
\hline \multirow{16}{*}{ 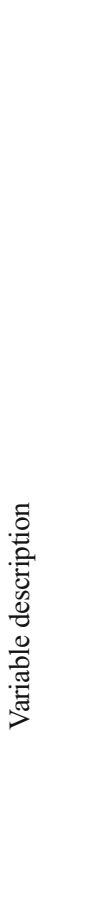 } & \multirow{15}{*}{ 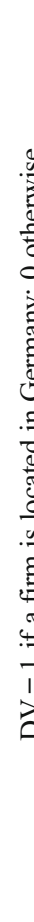 } & \multirow{16}{*}{ 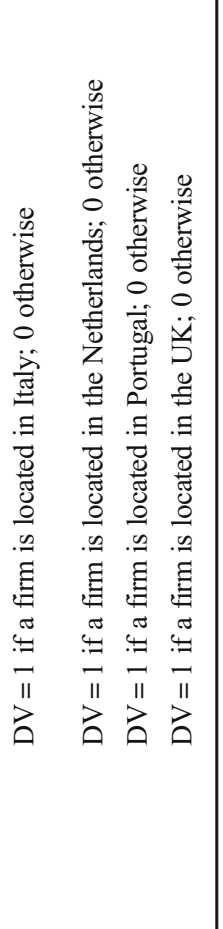 } & . & $\begin{array}{l}\text { Innovative sales, } \\
1-5 \% \text { of turnover }\end{array}$ & & $-0.015(0.171)$ \\
\hline & & & $\vec{z}$ & $\begin{array}{l}\text { Innovative sales, } \\
\quad 6-10 \% \text { of turnover }\end{array}$ & & $0.028(0.182)$ \\
\hline & & & $\begin{array}{l}0 \\
\ddot{0} \\
g\end{array}$ & $\begin{array}{l}\text { Innovative sales, } \\
\quad 11-15 \% \text { of turnover }\end{array}$ & & $-0.025(0.191)$ \\
\hline & & & : & $\begin{array}{l}\text { Innovative sales, } \\
16-25 \% \text { of turnover }\end{array}$ & & $0.011(0.184)$ \\
\hline & & & $\frac{\bar{g}}{=}$ & $\begin{array}{l}\text { Innovative sales, } \\
26-50 \% \text { of turnover }\end{array}$ & & $-0.177(0.213)$ \\
\hline & & & $\begin{array}{l}\vec{I} \\
\overrightarrow{0}\end{array}$ & $\begin{array}{l}\text { Innovative sales, } \\
>50 \% \text { of turnover }\end{array}$ & & $-0.126(0.195)$ \\
\hline & & & : & Product innovation & & $0.054(0.126)$ \\
\hline & & & के & Process innovation & & $-0.384 * * *(0.126)$ \\
\hline & & &. & $\begin{array}{l}\text { Organisational } \\
\text { innovation }\end{array}$ & & $0.056(0.101)$ \\
\hline & & & चे & $\begin{array}{l}\text { Marketing } \\
\text { innovation }\end{array}$ & & $0.043(0.078)$ \\
\hline & & & $\frac{0}{z}$ & Belong to a group & & $-0.021(0.109)$ \\
\hline & & & $\begin{array}{ll}\bar{n} \\
b\end{array}$ & Constant & $0.487 * * *(0.101)$ & $0.718 * * *(0.195)$ \\
\hline & & & 直 & $R^{2}$ & 0.07 & 0.14 \\
\hline & & & $\cong$ & No of obs. & 287 & 263 \\
\hline & & & 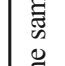 & $\begin{array}{l}\text { Ramsey RESET } \\
\text { test }\end{array}$ & Prob $>F=0.47$ & Prob $>F=0.82$ \\
\hline & & & 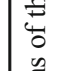 & $\begin{array}{l}\text { Variance inflation } \\
\text { factor (mean) }\end{array}$ & 1.51 & 2.02 \\
\hline
\end{tabular}

Notes: $* * * p<0.01, * * p<0.05, * p<0.10$ 
Open Access This article is distributed under the terms of the Creative Commons Attribution 4.0 International License (http:// creativecommons.org/licenses/by/4.0/), which permits unrestricted use, distribution, and reproduction in any medium, provided you give appropriate credit to the original author(s) and the source, provide a link to the Creative Commons license, and indicate if changes were made.

\section{References}

Abadie, A., \& Imbens, G.W. (2009). Matching on the estimated propensity score. NBER working paper no. 15301.

Acs, Z. J., Stam, E., Audretsch, D. B., \& O'Connor, A. (2017). The lineages of the entrepreneurial ecosystem approach. Small Business Economics, 49(1), 1-10. https://doi. org/10.1007/s11187-017-9864-8.

Afcha Chàvez, S. M. (2011). Behavioural additionality in the context of regional innovation policy in Spain. Innovation: Management, Policy and Practice, 13(1), 95-110. https://doi.org/10.5172/impp.2011.13.1.95.

Amara, N., \& Landry, R. (2005). Sources of information as determinants of novelty of innovation in manufacturing firms: evidence from the 1999 statistics Canada innovation survey. Technovation, 25, 245-259.

Antonioli, D., \& Marzucchi, A. (2012). Evaluating the additionality of innovation policy. A review focused on the behavioural dimension. World Review of Science, Technology and Sustainable Development, 9(2), 124-148. https://doi.org/10.1504/WRSTSD.2012.047685.

Antonioli, D., Marzucchi, A., \& Montresor, S. (2014). Regional innovation policy and innovative behaviour. Looking for additional effects. European Planning Studies, 22(1), 64 83. https://doi.org/10.1080/09654313.2012.722977.

Arranz, N., \& de Arroyabe, J. C. F. (2008). The choice of partners in $R \& D$ cooperation: an empirical analysis of Spanish firms. Technovation, 28(1-2), 88-100. https://doi.org/10.1016/j. technovation.2007.07.006.

Aschhoff, B., Fier, A., \& Fier, H. (2006). Detecting behavioural additionality - an empirical study on the impact of public $\mathrm{R} \& \mathrm{D}$ funding on firm's cooperative behaviour in Germany. ZEW discussion paper no. 06-037.

Autio, E., Gustafsson, R., \& Kanninen, S. (2008). First- and second-order additionality and learning outcomes in collaborative R\&D programs. Research Policy, 37(1), 59-76. https://doi.org/10.1016/j.respol.2007.07.012.

Barge-Gil, A. (2010). Cooperation-based innovators and peripheral cooperators: an empirical analysis of their characteristics and behavior. Technovation, 30(3), 195-206. https://doi. org/10.1016/j.technovation.2009.11.004.

Becker, S. O., \& Caliendo, M. (2007). mhbounds-sensitivity analysis for average treatment effects. Stata Journal, 7(1), 71-83.

Becker, S. O., \& Ichino, A. (2002). Estimation of average treatment effects based on propensity scores. Stata Journal, 2(4), 358-377.

van Beers, C., \& Zand, F. (2014). R\&D cooperation, partner diversity, and innovation performance: an empirical analysis.
Journal of Product Innovation Management, 31(2), 292312. https://doi.org/10.1111/jpim.12096.

Belderbos, R., Carree, M., \& Lokshin, B. (2004). Cooperative R\&D and firm performance. Research Policy, 33(10), 1477-1492. https://doi.org/10.1016/j.respol.2004.07.003.

Breschi, S., Cassi, L., Malerba, F., \& Vonortas, N. (2009). Networked research: European policy intervention in ICTs. Technology Analysis and Strategic Management, 21(7), 833857. https://doi.org/10.1080/09537320903182314.

Brown, R., \& Mason, C. (2017). Looking inside the spiky bits: a critical review and conceptualisation of entrepreneurial ecosystems. Small Business Economics, 49(1), 11-30. https://doi.org/10.1007/s11187-017-9865-7.

Buisseret, T. J., Cameron, H. M., \& Georghiou, L. (1995). What difference does it make - additionality in the public support of R-and-D in large firms. International Journal of Technology Management, 10(4-6), 587-600. https://doi. org/10.1504/IJTM.1995.025644.

Busom, I., \& Fernández-Ribas, A. (2008). The impact of firm participation in $\mathrm{R} \& \mathrm{D}$ programmes on $\mathrm{R} \& \mathrm{D}$ partnerships. Research Policy, 37(2), 240-257. https://doi.org/10.1016/j. respol.2007.11.002.

Caliendo, M., \& Kopeinig, S. (2008). Some practical guidance for the implementation of propensity score matching. Journal of Economic Surveys, 22(1), 31-72. https://doi.org/10.1111/j.1467-6419.2007.00527.

Cassiman, B., \& Veugelers, R. (2002). R\&D cooperation and spillovers: some empirical evidence from Belgium. American Economic Review, 92(4), 1169-1184. https://doi. org/10.1257/00028280260344704.

Cerulli, G. (2010). Modelling and measuring the effect of public subsidies on business R\&D: a critical review of the econometric literature. The Economic Record, 86(274), 421-449. https://doi.org/10.1111/j.1475-4932.2009.00615.

Cerulli, G., \& Potí, B. (2012). Evaluating the robustness of the effect of public subsidies on firms' R\&D: an application to Italy. Journal of Applied Economics, 15(2), 287-320. https://doi.org/10.1016/S1514-0326(12)60013-0.

Chaminade, C., Lundvall, B.-A., \& Haneef, S. (2018). National innovation systems. Cheltenham: Edward Elgar.

Chesbrough, H. (2003). Open innovation: the new imperative for creating and profiting from technology. Boston: Harvard Business School Publishing Corporation.

Chun, H., \& Mun, S.-B. (2012). Determinants of R\&D cooperation in small and medium-sized enterprises. Small Business Economics, 39(2), 419-436. https://doi.org/10.1007/s11187010-9312-5.

Clarysse, B., Wright, M., \& Mustar, P. (2009). Behavioural additionality of R\&D subsidies: a learning perspective. Research Policy, 38(10), 1517-1533. https://doi. org/10.1016/j.respol.2009.09.003.

Czarnitzki, D., \& Lopes-Bento, C. (2013). Value for money? New microeconometric evidence on public $\mathrm{R} \& \mathrm{D}$ grants in Flanders. Research Policy, 42(1), 76-89. https://doi. org/10.1016/j.respol.2012.04.008.

Czarnitzki, D., \& Delanote, J. (2015). R\&D policies for young SMEs: input and output effects. Small Business Economics, 45, 465-485. https://doi.org/10.1007/s11187-015-9661-1.

Davenport, S., Grimes, C., \& Davies, J. (1998). Research collaboration and behavioural additionality: a New Zealand case 
study. Technology Analysis \& Strategic Management, 10, 55-67. https://doi.org/10.1080/09537329808524304.

David, P. A., Hall, B. H., \& Toole, A. A. (2000). Is public R\&D a complement or substitute for private R\&D? A review of the econometric evidence. Research Policy, 29(4-5), 497-529. https://doi.org/10.1016/s0048-7333(99)00087-6.

Dhont-Peltrault, E., \& Pfister, E. (2011). R\&D cooperation versus R\&D subcontracting: empirical evidence from French survey data. Economics of Innovation and New Technology, 20(4), 309-341. https://doi.org/10.1080/10438591003669743.

DiPrete, T. A., \& Gangl, M. (2004). Assessing bias in the estimation of causal effects: Rosenbaum bounds on matching estimators and instrumental variables estimation with imperfect instruments. Sociological Methodology, 34(1), 271-310. https://doi.org/10.1111/j.0081-1750.2004.00154.x.

Durst, S. \& Poutanen, P. (2013). Success factors of innovation ecosystems - initial insights from a literature review. In Smeds, R. \& Irrmann, O. (Eds.) Co-create 2013: the boundary-crossing conference on co-design in innovation (pp. 27-38). Department of Industrial Engineering and Management, Aalto University, Publication series Science + Technology 15/2013

European Commission (2015). European service innovation centre: Acronyms and definitions. Available at: https://ec.europa. eu/enterprise/initiatives/esic/about/keywords/index_en.htm.. Accessed 25 August 2018.

Faems, D., van Looy, B., \& Debackere, K. (2005). Interorganizational collaboration and innovation: toward a portfolio approach. Journal of Product Innovation Management, 22(3), 238-250. https://doi.org/10.1111 j.0737-6782.2005.00120.

Falk, R. (2007). Measuring the effects of public support schemes on firms' innovation activities: survey evidence from Austria. Research Policy, 36(5), 665-679. https://doi.org/10.1016/j. respol.2007.01.005.

Fernández-Ribas, A., \& Shapira, P. (2009). The role of national and regional-level innovation programs in stimulating international cooperation in innovation. International Journal of Technology Management, 48(4), 473-498. https://doi. org/10.1504/IJTM.2009.02669.

Fier, A., Aschhoff, B., \& Löhlein, H. (2006). Behavioural additionality of public R\&D funding in Germany. In OECD (Ed.), Government R\&D funding and company behaviour: measuring behavioural additionality (pp. 127-149). Paris: OECD Publishing.

Foreman-Peck, J. (2013). Effectiveness and efficiency of SME innovation policy. Small Business Economics, 41(1), 55-70. https://doi.org/10.1007/s11187-012-9426-z.

Garcia, A., \& Mohnen, P. (2010). Impact of government support on R\&D and innovation. UNU-MERIT working paper no. 2010-034.

Georghiou, L. (2002). Additionality and impact of R\&D subsidies. IWT Studies, 40, 57-64.

Georghiou, L. (2004). Evaluation of behavioural additionality. Concept paper. IWT-Studies, 48, 7-22.

Georghiou, L., \& Clarysse, B. (2006). Behavioural additionality of R\&D grants: introduction and synthesis. In OECD (Ed.), Government $R \& D$ funding and company behaviour: measuring behavioural additionality (pp. 9-38). Paris: OECD Publishing.
Gobble, M. M. (2014). Charting the innovation ecosystem. Research-Technology Management, 57(4), 55-59. https://doi.org/10.5437/08956308X5704005.

Gomes, L., Facin, A., Salerno, M., \& Ikenami, R. (2016). Unpacking the innovation ecosystem construct: evolution, gaps and trends. Technological Forecasting and Social Change. https://doi.org/10.1016/j.techfore.2016.11.009.

Gök, A., \& Edler, J. (2012). The use of behavioural additionality evaluation in innovation policy making. Research Evaluation, 21(4), 306-318. https://doi.org/10.1093/reseval/rvs015.

Guo, S., \& Fraser, M. W. (2010). Propensity score analysis: statistical methods and applications. Thousand Oaks: Sage.

Hagedoorn, J. (1993). Understanding the rationale of strategic technology partnering: inter-organizational modes of cooperation and sectoral differences. Strategic Management Journal, 14(2), 371-385. https://doi.org/10.1002/smj.4250140505.

Hall, B. H., \& Maffioli, A. (2008). Evaluating the impact of technology development funds in emerging economies: evidence from Latin America. European Journal of Development Research, 20, 172-198. https://doi. org/10.1080/09578810802060819.

Herrera, L., \& Nieto, M. (2008). The national innovation policy effect according to firm location. Technovation, 28(8), 540 550. https://doi.org/10.1016/j.technovation.2008.02.009.

Hoffmann, W. H., \& Schlosser, R. (2001). Success factors of strategic alliances in small and medium-sized enterprisesan empirical study. Long Range Planning, 34(3), 357-381. https://doi.org/10.1016/S0024-6301(01)00041-3.

Hsu, F. M., Horng, D. J., \& Hsueh, C. C. (2009). The effect of government-sponsored R\&D programmes on additionality in recipient firms in Taiwan. Technovation, 29(3), 204-217. https://doi.org/10.1016/j.technovation.2008.05.001.

Ichino, A., Mealli, F., \& Nannicini, T. (2008). From temporary help jobs to permanent employment: what can we learn from matching estimators and their sensitivity? Journal of Applied Econometrics, 23(3), 305-327. https://doi.org/10.1002/jae.998.

Imbens, G. W. (2004). Nonparametric estimation of average treatment effects under exogeneity: a review. Review of Economics and Statistics, 86(1), 4-29. https://doi. org/10.1162/003465304323023651.

Lee, S., Park, G., Yoon, B., \& Park, J. (2010). Open innovation in SMEs - an intermediated network model. Research Policy, 39(2), 290-300. https://doi.org/10.1016/j.respol.2009.12.009.

Leiponen, A., \& Byma, J. (2009). If you cannot block, you better run: small firms, cooperative innovation, and appropriation strategies. Research Policy, 38(9), 1478-1488. https://doi. org/10.1016/j.respol.2009.06.003.

Lhuillery, S., \& Pfister, E. (2009). R\&D cooperation and failures in innovation projects: empirical evidence from French CIS data. Research Policy, 38(1), 45-57. https://doi.org/10.1016/j. respol.2008.09.002.

Mantel, N., \& Haenszel, W. (1959). Statistical aspects of the analysis of data from retrospective studies of disease. Journal of the National Cancer Institute, 22(4), 719-748. https://doi.org/10.1093/jnci/22.4.719.

Mazzucato, M. (2016). Innovation, the state and patient capital. In M. Mazzucato \& M. Jacobs (Eds.), Rethinking capitalism (pp. 98-118). Chichester: Wiley.

Millimet, D. L., \& Tchernis, R. (2009). On the specification of propensity scores, with applications to the analysis of trade 
policies. Journal of Business and Economic Statistics, 27(3), 397-415. https://doi.org/10.1198/jbes.2009.06045.

Miotti, L., \& Sachwald, F. (2003). Co-operative R\&D: why and with whom? An integrated framework of analysis. Research Policy, 32(8), 1481-1499. https://doi.org/10.1016/S00487333(02)00159-2.

Nannicini, T. (2007). A simulation-based sensitivity analysis for matching estimators. Stata Journal, 7(3), 334-350.

Nieto, M., \& Santamaria, L. (2007). The importance of diverse collaborative networks for the novelty of product innovation. Technovation, 27(6-7), 367-377. https://doi.org/10.1016/j. technovation.2006.10.001.

O'Connor, G. C. (2008). Open, radical innovation: toward an integrated model in large established firms. In $\mathrm{H}$. Chesbrough, W. Vanhaverbeke, \& J. West (Eds.), Open innovation: researching a new paradigm (pp. 62-82). Oxford: Oxford University Press.

O'Connor, G. C., \& DeMartino, R. (2006). Organizing for radical innovation: an exploratory study of the structural aspects of RI management systems in large established firms. Journal of Product Innovation Management, 23(6), 475-497. https://doi.org/10.1111/j.1540-5885.2006.00219.

OECD. (2005). Oslo manual: guidelines for collecting and interpreting innovation data. Paris: OECD Publishing.

OECD. (2006). Government R\&D funding and company behaviour: measuring behavioural additionality. Paris: OECD Publishing.

Oh, D.-S., Philips, F., Lee, S., \& Lee, E. (2016). Innovation ecosystems: a critical examination. Technovation, 54, 1-6. https://doi.org/10.1016/j.technovation.2016.02.004.

Papaioannou, T., Wield, D., \& Chataway, J. (2009). Knowledge ecologies and ecosystems? An empirically grounded reflection on recent developments in innovation systems theory. Environment and Planning C: Government and Policy, 27(2), 319-339. https://doi.org/10.1068/c0832.

Phelps, E. (2015). What is wrong with the West's economies? New York Review of Books, LXII(13), 54-56.

Phelps, C. C., \& Paris, H. E. C. (2010). A longitudinal study of the influence of alliance network structure and composition on firm exploratory innovation. Academy of Management Journal, 53, 890-913.

Radicic, D., Pugh, G., Hollanders, H., Wintjes, R., \& Fairburn, J. (2016). The impact of innovation support programmes on SME innovation in traditional manufacturing industries: an evaluation for seven EU regions. Environment and Planning C: Government and Policy, 34(8), 1425-1452.

Rese, A., \& Baier, D. (2011). Success factors for innovation management in networks of small and medium enterprises. $R \& D$ Management, 41(2), 138-155. https://doi.org/10.1111/j.14679310.2010.00620.x.

Rosenbaum, P. R. (2002). Observational studies. New York: Springer.

Scaringella, L., \& Radziwon, A. (2018). Innovation, entrepreneurial, knowledge, and business ecosystems: old wine in new bottles? Technological Forecasting and Social Change. https://doi.org/10.1016/j.techfore.2017.09.023.

Schumpeter, J. (1942). Capitalism, socialism, and democracy. New York: Harper \& Bros.

Song, J. (2016). Innovation ecosystem: impact of interactive patterns, member location and member heterogeneity on cooperative innovation performance. Innovation: Management, Policy and Practice, 18(1), 13-29.

Steiner, P. M., Cook, T. D., Shadish, W. R., \& Clark, M. H. (2010). The importance of covariate selection in controlling for selection bias in observational studies. Physiological Methods, 15(3), 250-267. https://doi.org/10.1037/a0018719.

Tassey, G. (2010). Rationales and mechanisms for revitalizing US manufacturing R\&D strategies. Journal of Technology Transfer, 35, 283-333.

Teirlinck, P., \& Spithoven, A. (2012). Fostering industry-science cooperation through public funding: differences between universities and public research centres. Journal of Technology Transfer, 37(5), 676-695. https://doi. org/10.1007/s10961-010-9205-4.

Tellis, G. J. (2013). Unrelenting innovation: how to create a culture for market dominance. New York: Wiley.

Tether, B. S. (2002). Who cooperates for innovation, and why. An empirical analysis. Research Policy, 31, 947-967. https://doi. org/10.1016/S0048-7333(01)00172-X.

Tether, B. S., \& Tajar, A. (2008). Beyond industry-university links: sourcing knowledge for innovation from consultants, private research organisations and the public science-base. Research Policy, 37, 1079-1095. https://doi.org/10.1016/j. respol.2008.04.003.

Un, C. A., Cuervo-Cazurra, A., \& Asakawa, K. (2010). R\&D collaborations and product innovation. Journal of Product Innovation Management, 27(5), 673-689. https://doi. org/10.1111/j.1540-5885.2010.00744.x.

Von Hippel, E. (1988). The sources of innovation. New York: Oxford University Press.

Wanzenböck, I., Scherngell, T., \& Fischer, M. M. (2013). How do firm characteristics affect behavioural additionalities of public R\&D subsidies? Evidence from the Austrian transport sector. Technovation, 33(2-3), 66-77. https://doi. org/10.1016/j.technovation.2012.11.006.

Williamson, O. E. (1985). The economic institutions of capitalism. New York: The Free Press.

Xu, G., Wu, Y., Minshall, T., \& Zhou, Y. (2018). Exploring innovation ecosystems across science, technology, and business: a case of 3D printing in China. Technological Forecasting and Social Change. https://doi.org/10.1016/j. techfore.2017.06.030.

Zeng, S. X., Xie, X. M., \& Tam, C. M. (2010). Relationship between cooperation networks and innovation performance of SMEs. Technovation, 30(3), 181-194. https://doi. org/10.1016/j.technovation.2009.08.003. 